medRxiv preprint doi: https://doi.org/10.1101/2021.03.31.21254634; this version posted April 5, 2021. The copyright holder for this preprint (which was not certified by peer review) is the author/funder, who has granted medRxiv a license to display the preprint in perpetuity. It is made available under a CC-BY-NC-ND 4.0 International license .

\title{
SLAMP: A Rapid Fluorometric RT-LAMP Assay for Sensitive and Specific Detection of SARS- CoV-2 from Human Saliva
}

Authors:

D. A. Bikos ${ }^{a, b}$, C. Hwang ${ }^{b}$, K. A. Brileya ${ }^{b}$, A. Parker ${ }^{b, d}$, E. K. Loveday ${ }^{a, b}$, M. Rodriguez ${ }^{c}$, T. LeFevre ${ }^{a, b}$, I. Thornton $^{a, b}$, J. N. Wilking ${ }^{a, b}$, M. Dills, S. T. Walk ${ }^{c}$, A. K. Adams ${ }^{e}$, R. Plowright ${ }^{c}$, A. B. Hoegh ${ }^{d}$, J. R. Carter ${ }^{f}$, J.

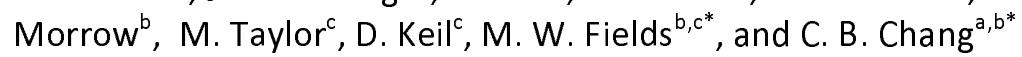

\author{
Affiliations: \\ United States \\ States \\ 59717, United States

\section{*Co-corresponding authors:} \\ Connie B. Chang \\ Department of Chemical and Biological Engineering \\ Center for Biofilm Engineering \\ Montana State University \\ Matthew W. Fields \\ Department of Microbiology and Immunology \\ Center for Biofilm Engineering \\ Montana State University
}

aDepartment of Chemical and Biological Engineering, Montana State University, Bozeman, MT 59717,

${ }^{\mathrm{b}}$ Center for Biofilm Engineering, Montana State University, Bozeman, MT 59717, United States

'Department of Microbiology \& Immunology, Montana State University, Bozeman, MT 59717, United

${ }^{\mathrm{d} D e p a r t m e n t}$ of Mathematical Sciences, Montana State University, Bozeman, MT 59717, United States

${ }^{\circ}$ Center for American Indian and Rural Health Equity (CAIRHE), Montana State University, Bozeman, MT

${ }^{f}$ Health \& Human Development, Montana State University, Bozeman, MT 59717, United States

\begin{abstract}
.
Rapid testing methods can identify outbreaks and trigger preventive strategies for slowing the spread of SARS-CoV-2, the virus that causes COVID-19. The "gold-standard" detection method for SARS-CoV-2 is reverse transcription quantitative polymerase chain reaction (RT-qPCR) performed on samples collected using a nasopharyngeal (NP) swab. While NP RT-qPCR provides high sensitivity, it requires trained personnel to administer and suffers from lengthy time-to-result. Recently, the testing community has turned to rapid saliva-based screening methods including saliva-to-RT-qPCR and/or saliva-to-RT-LAMP (reverse transcription loop-mediated isothermal amplification) to identify infected individuals regardless of symptomatic presentation. Here, we report a simple and rapid RT-LAMP fluorometric assay performed directly on heat-inactivated saliva, without the addition of buffers or proteinase $\mathrm{K}$ treatments we call saliva LAMP (SLAMP). Over the course of two days, a total of 243 individuals were tested using NP RT-qPCR, saliva-based qPCR, and saliva-based RT-LAMP. Of the 243 NP RT-qPCR tests, 65 were positive, 178 were negative, and SLAMP demonstrated a $91 \%$ sensitivity and $98 \%$ specificity. SLAMP sensitivity becomes $95 \%$ when samples negative in saliva tests while positive in NP RT-qPCR are excluded from evaluation, potentially indicating significant differences in viral titer between collection sites on the body. SLAMP is performed in triplicates and takes $45 \mathrm{~min}$ to run in the laboratory, requiring less technician time and instrument run time than NP RT-qPCR. These results demonstrate that saliva-based RT-LAMP can enable frequent and rapid screening of large numbers of people to identify presymptomatic and asymptomatic individuals thereby controlling outbreaks.
\end{abstract}


medRxiv preprint doi: https://doi.org/10.1101/2021.03.31.21254634; this version posted April 5, 2021. The copyright holder for this preprint (which was not certified by peer review) is the author/funder, who has granted medRxiv a license to display the preprint in perpetuity. It is made available under a CC-BY-NC-ND 4.0 International license .

\section{Introduction.}

COVID-19, the disease caused by the SARS-CoV-2 virus, ${ }^{1}$ has developed into a worldwide pandemic threatening public health, economics, and quality of life. Viral spread can be controlled by deploying population-level nucleic acid amplification testing (NAAT) per day at a population-level to rapidly identify infected individuals. NAATs have helped stop viral transmission, enabled contact tracing, and permitted safer global movement. However, inexpensive, widely available, and rapid tests are needed to help reopen our communities. Currently, the "gold-standard" method for the detection of SARS-CoV-2 is reverse transcription quantitative polymerase chain reaction (RT-qPCR). However, the RT-qPCR test requires significant reagent consumption, specialized equipment, trained operators, and several hours to perform. Expanding surveillance across a global scale calls for new testing strategies that are inexpensive, minimize reagent consumption, decrease assay time, and allow for simple monitoring without requiring trained personnel.

A particularly exciting NAAT alternative to RT-qPCR is reverse transcriptase loop-mediated isothermal amplification (RT-LAMP). RT-LAMP is an isothermal technique for the exponential amplification of RNA. LAMP reactions use 4-6 primers, enhancing assay specificity. Typically performed at fixed temperature between $60^{\circ} \mathrm{C}$ and $65^{\circ} \mathrm{C}$, RT-LAMP simplifies NAAT testing and removes the longer times and technical barriers of thermal cycling at higher temperatures required by $\mathrm{PCR}$-based methods ${ }^{2-7}$. Amplification is much faster than traditional $\mathrm{PCR}$, even when large amounts of non-target RNA are present in the collected specimen, as is the case for blood, serum, saliva, and wastewater. The RT-LAMP assay is completed within 45 min, and exceptionally high viral loads can be detected within 5 min using either colorimetric or fluorometric detection methods.

Here, we present a simple saliva LAMP testing method we call SLAMP, a rapid RT-LAMP fluorometric assay performed directly on heat-inactivated saliva, without the addition of buffers or proteinase $\mathrm{K}$ treatments. Saliva samples containing SARS-CoV-2 virus are inactivated and optimally lysed by heating at $95^{\circ} \mathrm{C}$ for 15 min post-collection, before adding directly to an RTLAMP assay. Through the systematic testing of additives including guanidine $\mathrm{HCl}$, UDG/dUTP, and optimizing primer design, we have developed a workflow that enables sensitive RT-LAMP detection of SARS-CoV-2 RNA direct from saliva. We report the findings of a multi-day pilot study of 243 individuals in which we perform a direct comparison of these individuals sampled using nasopharyngeal (NP) RT-qPCR and SLAMP. Of the 243 tests, 65 were positive and 178 were negative under NP RT-qPCR. The study was performed alongside existing campus NP RT-qPCR SARS-CoV-2 testing at Montana State University (MSU) in Bozeman, MT, USA during November 2020. We also compare SLAMP to SalivirDetect, a direct saliva-to-qPCR assay in which saliva is heated for $45 \mathrm{~min}$ in an oven and directly added to an RT-qPCR reaction. Both saliva tests are compared to the "gold standard" NP RT-qPCR. SLAMP tests are performed in triplicate, significantly decreasing the false negative rate. Of the 243 tests, 65 were positive and 178 were negative under NP RT-qPCR. When compared to the NP RT-qPCR, we report that SLAMP can achieve SARS-CoV-2 RNA detection in saliva with a sensitivity and specificity of $91 \%$ and $98 \%$, respectively. SalivirDetect achieved a sensitivity and specificity of $89 \%$ and $97 \%$, respectively. When positive samples that were detected in NP RT-qPCR but not in SLAMP nor SalivirDetect were excluded, implying a significant difference in virus titer between collection sites on the body, SLAMP achieved a 95\% sensitivity. Additionally, when NP RT-qPCR-positive test subjects at $\mathrm{Ct} \geq 33$ measured under SalivirDetect used toothpaste or consumed gum, yoghurt, or coffee and were excluded, SalivirDetect sensitivity increased to $96 \%$. SLAMP requires minimal reagents and transfer steps to perform. The method can be an effective screening test for universities and other organizations interested in identifying asymptomatic or pre-symptomatic carriers of SARS-CoV-2. Importantly, SLAMP does not 
medRxiv preprint doi: https://doi.org/10.1101/2021.03.31.21254634; this version posted April 5, 2021. The copyright holder for this preprint (which was not certified by peer review) is the author/funder, who has granted medRxiv a license to display the preprint in perpetuity. It is made available under a CC-BY-NC-ND 4.0 International license .

require trained medical personnel to collect samples, as in the case of nasopharyngeal (NP) swabs. Subjects can self-collect saliva for mail-in or drive-through testing, thereby minimizing contact between testing staff and potentially infectious individuals. SLAMP lowers the overall need for personnel and personal protective equipment, significantly reducing costs.

\section{MATERIALS AND METHODS}

\section{Saliva sample collection and SLAMP assay workflow.}

Nasopharyngeal (NP) swab samples and saliva sample collection took place at the Montana State University (MSU) symptomatic testing site in Bozeman, MT, USA between the days of mid-November 2020 under MSU IRB approval. Volunteers for the pilot study were provided with a 3D-printed accessory caddy containing a 30-mL polypropylene medicine cup (MedPride 97205), a 1-mL transfer pipet (Szsrcywd kkll), and a screw cap tube (VWR 16466-040). Saliva was first expressed into a medicine cup with wide opening (Figure 1i) before using the pipet to transfer $\approx 1.0 \mathrm{~mL}$ of saliva into the screw-cap tube (Figure 1ii). Tubes were indexed with adhesive labels (Electronic Imaging Materials, Inc. 667) prepared via barcode printer (TSC MB340T) and transported to the lab in hard-sided coolers. $70 \%$ ethanol sprays were frequently used to decontaminate surfaces. The samples were heat-treated within a biosafety cabinet using a heat block (Labnet AccuBlock) at $95^{\circ} \mathrm{C}$ for $15 \mathrm{~min}$ to inactivate the viruses (Figure 1iii). Samples were removed from heat treatment and left at room temperature for 20 min to allow debris in the saliva to settle to the bottom of the tubes. Barcodes were read to the database using a handheld barcode scanner (Motorola Symbol LS2208-SR20007R-NA). Each 5- $\mu \mathrm{L}$ sample was added to $20 \mu \mathrm{L}$ of RT-LAMP solution (NEB) in a 96-well qPCR plate (MicroAmp EnduraPlate Optical 96-well Fast Clear Reaction Plate with Barcode, 4483485) before being read on a QuantStudio ${ }^{\mathrm{TM}} 3$ Real-Time PCR System (Applied Biosystems) (Figure 1iv).

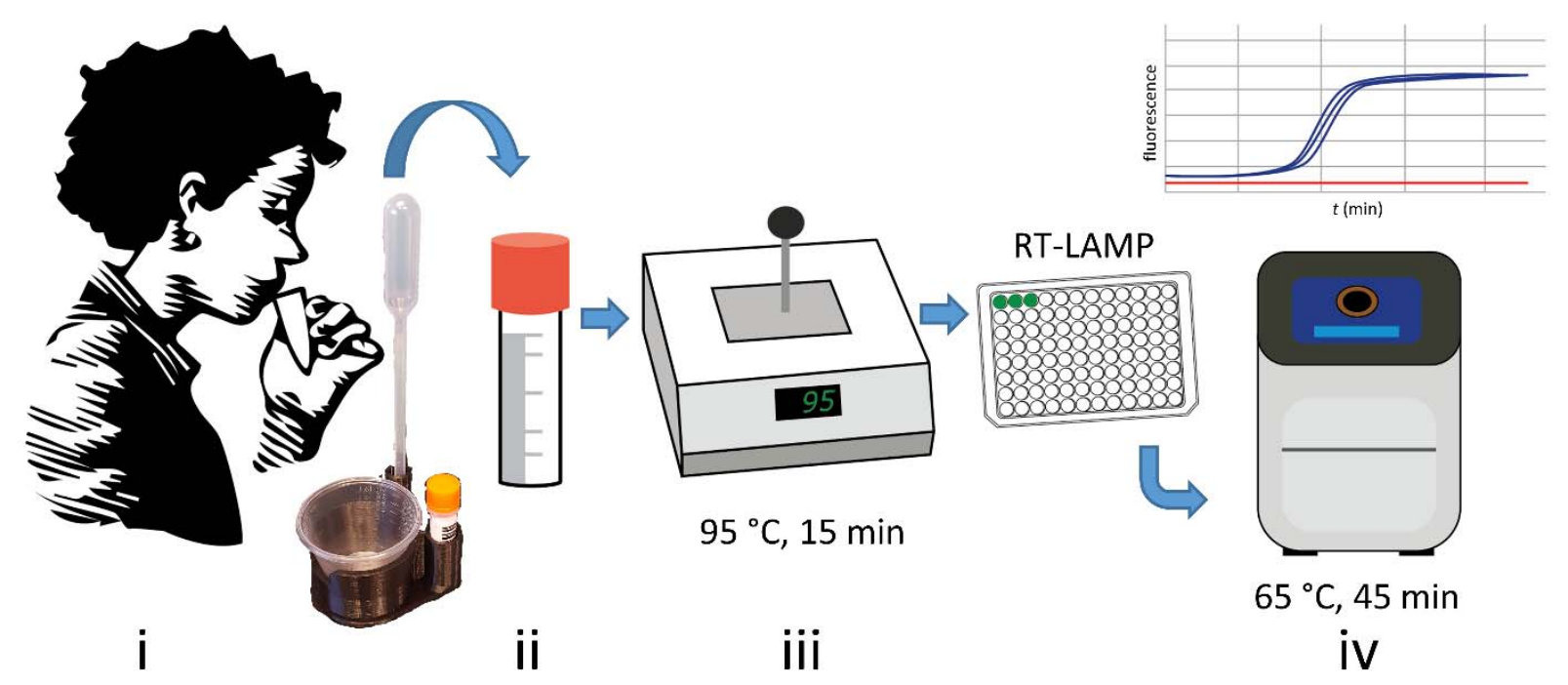

Figure 1. SLAMP testing workflow. (i) $1 \mathrm{~mL}$ saliva is expressed directly into medicine cup before being pipetted (ii) into screw cap sample tube. (iii) Virus inactivation is performed directly on the saliva in the tube without any added buffers in a heat block at $95{ }^{\circ} \mathrm{C}$ for $15 \mathrm{~min}$. Each sample is pipetted in triplicate RT-LAMP reactions in a qPCR machine (iv) at $65{ }^{\circ} \mathrm{C}$ for $45 \mathrm{~min}$.

\section{Subject questionnaire.}

Test subjects were provided with a self-reported questionnaire (SI Methods) for age, gender, race, and ethnicity information. Additionally, subjects were asked to confirm whether they were currently symptomatic or asymptomatic and whether they had known contact with infected 
medRxiv preprint doi: https://doi.org/10.1101/2021.03.31.21254634; this version posted April 5, 2021. The copyright holder for this preprint (which was not certified by peer review) is the author/funder, who has granted medRxiv a license to display the preprint in perpetuity. It is made available under a CC-BY-NC-ND 4.0 International license .

individuals. Finally, subjects were asked to disclose if, in the last $30 \mathrm{~min}$, they had eaten, drank, or used mouthwash, chewing gum/lozenge, smoked, chewed tobacco, or brushed teeth.

\section{D-printed caddy accessory for efficient saliva collection.}

To facilitate drive-through saliva collection, each subject was provided a 3D-printed caddy accessory containing a medicine cup, transfer pipet, and sample tube (SI Figure 1A). Accessory designs were optimized for low cost and high throughput, enabling printing of five caddies at a time (SI Figure 1B). Accessories were manufactured using an SLA 3D-printer (Formlabs, Form 2 and 3) loaded with clear UV cross-linkable resin (Formlabs, RS-F2-GPCL-04), soaked in isopropanol for $20 \mathrm{~min}$, and post-cured under UV light (Formlabs, Form Cure FH-CU-01) at 60 ${ }^{\circ} \mathrm{C}$ for $15 \mathrm{~min}$. Drainage holes were included at the bottom of each caddy to drain excess resin during printing and post-processing and drain $70 \%$ ethanol during decontamination. 3D models and print files are available as supplementary material.

\section{Duplex RT-LAMP primers for SARS-CoV-2 detection and internal control}

All primers were based on New England Biolabs designs ${ }^{8}$, ordered from Integrated DNA Technologies (Coralville, IA, USA), and resuspended to $100 \mu \mathrm{M}$ in nuclease-free water (NEB B1500L). All primers were desalted except FIP and BIP sequences, which were HPLC purified. For 100 reactions, the SARS-CoV-2 primer sets (N2, E1) were prepared as a duplex primer mix in the following manner: $40 \mu \mathrm{L}$ of FIP, $40 \mu \mathrm{L}$ of BIP, $10 \mu \mathrm{L}$ of LF, $10 \mu \mathrm{L}$ of LB, $5 \mu \mathrm{L}$ of $\mathrm{F} 3,5 \mu \mathrm{L}$ of $\mathrm{B} 3$, and $30 \mu \mathrm{L}$ nuclease-free water $(250 \mu \mathrm{L}$ total volume). A third internal control primer set targeting human beta-actin (ACTB) was also similarly prepared, except with the addition of 140 $\mu \mathrm{L}$ of nuclease-free water $(250 \mu \mathrm{L}$ total volume). The prepared working primer solutions thus consisted of $16 \mu \mathrm{M}$ of each FIP and BIP, $4 \mu \mathrm{M}$ of each LF and LB, and $2 \mu \mathrm{M}$ of each F3 and B3. The primer stocks and prepared working primer solutions were stored at $-20^{\circ} \mathrm{C}$ until use.

\begin{tabular}{|l|l|}
\hline Primers & Sequence 5'-3' \\
\hline N2_FIP & TTCCGAAGAACGCTGAAGCGGAACTGATTACAAACATTGGCC \\
\hline N2_BIP & CGCATTGGCATGGAAGTCACAATTTGATGGCACCTGTGTA \\
\hline N2_F3 & ACCAGGAACTAATCAGACAAG \\
\hline N2_B3 & GACTTGATCTTTGAAATTTGGATCT \\
\hline N2_LF & GGGGGCAAATTGTGCAATTTG \\
\hline N2_LB & CTTCGGGAACGTGGTTGACC \\
\hline E1_FIP & ACCACGAAAGCAAGAAAAAGAAGTTCGTTTCGGAAGAGACAG \\
\hline E1_BIP & TTGCTAGTTACACTAGCCATCCTTAGGTTTTACAAGACTCACGT \\
\hline E1_F3 & TGAGTACGAACTTATGTACTCAT \\
\hline E1_B3 & TTCAGATTTTTAACACGAGAGT \\
\hline E1_LF & CGCTATTAACTATTAACG \\
\hline E1_LB & GCGCTTCGATTGTGTGCGT \\
\hline
\end{tabular}


medRxiv preprint doi: https://doi.org/10.1101/2021.03.31.21254634; this version posted April 5, 2021. The copyright holder for this preprint (which was not certified by peer review) is the author/funder, who has granted medRxiv a license to display the preprint in perpetuity. It is made available under a CC-BY-NC-ND 4.0 International license .

\begin{tabular}{|l|l|}
\hline ACTB_FIP & GAGCCACACGCAGCTCATTGTATCACCAACTGGGACGACA \\
\hline ACTB_BIP & CTGAACCCCAAGGCCAACCGGCTGGGGTGTTGAAGGTC \\
\hline ACTB_F3 & AGTACCCCATCGAGCACG \\
\hline ACTB_B3 & AGCCTGGATAGCAACGTACA \\
\hline ACTB_LF & TGTGGTGCCAGATTTTCTCCA \\
\hline ACTB_LB & CGAGAAGATGACCCAGATCATGT \\
\hline
\end{tabular}

\section{Fluorescent RT-LAMP Reactions.}

RT-LAMP reactions were set up as described by NEB protocol E1700 (New England Biolabs, Ipswich, MA, USA) at $25 \mu \mathrm{L}$ reaction volume with the following modifications: $12.5 \mu \mathrm{L}$ Warm Start $2 \mathrm{X}$ Master Mix, $0.175 \mu \mathrm{L}$ of dUTP, $0.5 \mu \mathrm{L}$ of UDG, $2.5 \mu \mathrm{L}$ of primer mix, $0.5 \mu \mathrm{L} 25 \mu \mathrm{M}$ SYTO-9 (Invitrogen SYTO-9 Green Fluorescent Nucleic Acid Stain, cat no. S34854) 0.25 L of ROX reference dye for qPCR (Lumiprobe, Hunt Valley, MD, USA), $2.5 \mu \mathrm{L}$ of $0.4 \mathrm{M}$ molecular biology grade guanidine $\mathrm{HCl}(\mathrm{GuHCl}$, final concentration $40 \mathrm{mM}$ ) (Alfa Aesar J65661), $1.075 \mu \mathrm{L}$ of nuclease-free water (NEB), and $5 \mu \mathrm{L}$ of saliva sample. The reactions were performed in a QuantStudio $^{\mathrm{TM}} 3$ Real-Time PCR System (Applied Biosystems) for 45 min and monitored every 1 min for fluorescence in the FAM channel. Triplicate reactions were set up for each saliva sample. Controls were run on each 96 well plate, including virus-free, heat-treated human saliva as a no-template control for SARS-CoV-2 and a positive internal control for human beta-actin (ACTB). The positive control was fragment 1 of the synthetic SARS-CoV-2 RNA provided by the National Institute of Standards and Technology (NIST) (RGTM 10169, $5 \times 10^{6}$ RNA copies per microliter). The positive control was diluted in virus-free saliva so that there were $5 \times 10^{4}, 5 \times$ $10^{2}$, or 5 copies/ $\mu \mathrm{L}$ in the reaction mix.

\section{NEB Luna Kit RT-qPCR Reactions.}

All RT-qPCR reactions used for SLAMP standard curve comparisons were prepared according to manufacturer protocol (NEB E3006L): $10 \mu \mathrm{L}$ of Luna Universal Probe One-Step Reaction Mix $(2 \times), 1 \mu \mathrm{L}$ of Luna Warm Start RT Enzyme Mix (200x), $4 \mu \mathrm{L}$ of primer mix, and $5 \mu \mathrm{L}$ of template for a final reaction volume of $20 \mu \mathrm{L}$. The CDC N1 forward primer was GACCCCAAAATCAGCGAAAT, CDC N1 reverse primer TCTGGTTACTGCCAGTTGAATCTG, and probe FAM-ACCCCGCATTACGTTTGGTGGACC-BHQ1. The primer mix was prepared from a $20 \mu \mathrm{M}$ stock of each primer and constituted the following: $0.4 \mu \mathrm{L}$ of both forward and reverse primers $(0.4 \mu \mathrm{M}$ final concentration), $0.2 \mu \mathrm{L}$ of probe $(0.2 \mu \mathrm{M}$ final concentration), $0.5 \mu \mathrm{L}$ of UDG, and $2.5 \mu \mathrm{L}$ of nuclease-free water. The reactions were performed in a QuantStudio 7 Real-Time PCR system with the following thermocycler conditions: reverse transcription at 55 ${ }^{\circ} \mathrm{C}$ for $10 \mathrm{~min}$, initial denaturation at $95^{\circ} \mathrm{C}$ for $1 \mathrm{~min}$, followed by 44 cycles of denaturation at 95 ${ }^{\circ} \mathrm{C}$ for $10 \mathrm{~s}$, extension at $55^{\circ} \mathrm{C}$ for $30 \mathrm{~s}$, and plate read. The data was analyzed using Design \& Analysis Software, Release Version: 2.5.0, Copyright 2020 Thermo Fisher Scientific.

\section{Curve fitting.}

RT-LAMP amplification curves were described by equation $\operatorname{Rn}(t)=a+(k-a)(1+\exp [-b(t-m)])$ where $\Delta \mathrm{Rn}(t)$ represents a scaled and baselined fluorescence intensity as a function of reaction time $t .{ }^{9}$ Fit parameters $a$ and $k$ define the lower and upper saturation limits, respectively, while $m$ and $b$ describe the $x$-coordinate and slope at the inflection point, respectively. The time-topositive Tp $=m-2 / b$ is derived from $m$ and $b$ fitting parameters and serves as an analog to the 
medRxiv preprint doi: https://doi.org/10.1101/2021.03.31.21254634; this version posted April 5, 2021. The copyright holder for this preprint (which was not certified by peer review) is the author/funder, who has granted medRxiv a license to display the preprint in perpetuity. It is made available under a CC-BY-NC-ND 4.0 International license .

familiar cycle threshold Ct used in qPCR results interpretation. Fitting was performed using KaleidaGraph v4.1 non-linear least squares routine.

\section{Synthetic vRNA standards for determining LOD.}

Standards were prepared from heat- and TCEP-inactivated saliva to protect RNA from endonucleases and represent ideal backgrounds. Final TCEP concentrations in reactions were $2.5 \mathrm{mM}$. Full-length synthetic genomic vRNA was purchased from Twist Biosciences (Control 9 Genbank ID: MT152824, GISAID ID: USA/WA2/2020).

\section{BSL-3 SARS-CoV-2 growth and heat inactivation of infectivity.}

Plaque assays (sensitivity limit 5 plaque-forming units (PFU)/mL) were performed on infectious solutions of USA/WA1/2020 strain (BEI Resources) SARS-CoV-2 serially diluted 10-fold in viral media which consists of $1 \times$ Dulbecco's Modified Eagle's Medium (DMEM), $2 \%$ fetal bovine serum (FBS), and 1× Pen Strep. Dilutions are inoculated onto susceptible E6-Vero cells (ATCC) and incubated for $1 \mathrm{~h}$ to facilitate infection. Subsequently, cells are overlaid with a diffusionlimiting agent composed of $0.75 \%$ methylcellulose and incubated at $37{ }^{\circ} \mathrm{C}$ for $3-4$ days. Viral replication causes "plaques" to form on the cell monolayer, the number of which correlate with infectivity present in the original sample. Heat treatment was conducted in $1.5 \mathrm{~mL}$ screw cap tubes from $1.5 \mathrm{~mL}$ of viral supernatant at $1.2 \times 10^{7} \mathrm{PFU} / \mathrm{mL}$ and temperatures were confirmed with thermometers and digital probes ${ }^{10}$.

\section{SalivirDetect RT-qPCR.}

SLAMP was compared to a saliva-to-RT-qPCR assay called SalivirDetect with FDA Emergency Use Authorization (EUA) application number EUA202615, submitted August 25, 2020 and developed by Drs. Phillip Buckhaults and Carolyn Banister (University of South Carolina). SalivirDetect, like SLAMP, uses heating at $95^{\circ} \mathrm{C}$ to process saliva without inactivation buffers or additives. SalivirDetect was conducted in the InHealth Life Sciences CLIA/CAP laboratory led by Dr. Deborah Keil (MSU). Briefly, $\approx 5 \mathrm{~mL}$ of saliva was collected in a $50 \mathrm{~mL}$ centrifuge tube. The tube was placed in a $95^{\circ} \mathrm{C}$ oven (Fisherbrand Isotemp General Purpose Heating and Drying Oven) for $45 \mathrm{~min}$, then allowed to sit at room temperature to cool. Two $5-\mu \mathrm{L}$ aliquots of the saliva were transferred to two wells in a 96-well plate containing RT-qPCR reagents, one well containing $\mathrm{N} 1$ primers and the second well containing human RNase $\mathrm{P}$ (RP) primers from the United States Center for Disease Control (US CDC) Real-Time Reverse Transcription PCR Panel for SARS-CoV-2 detection. Reactions were prepared using NEB Luna Kit as described above. Samples were run on a BioRad CFX96 qPCR machine.

\begin{tabular}{|l|l|}
\hline Primers & Sequence 5'-3' \\
\hline 2019-nCoV_N1-F & GACCCCAAAATCAGCGAAAT \\
\hline 2019-nCoV_N1-R & TCTGGTTACTGCCAGTTGAATCTG \\
\hline 2019-nCoV_N1-P & FAM-ACCCCGCATTACGTTTGGTGGACC-IBFQ \\
\hline RP-F & AGATTTGGACCTGCGAGCG \\
\hline RP-R & GAGCGGCTGTCTCCACAAGT \\
\hline RP-P & Cy5-TTCTGACCTGAAGGCTCTGCGCG-IBRQ \\
\hline
\end{tabular}

Nasopharyngeal (NP) swab RT-qPCR. 
medRxiv preprint doi: https://doi.org/10.1101/2021.03.31.21254634; this version posted April 5, 2021. The copyright holder for this preprint (which was not certified by peer review) is the author/funder, who has granted medRxiv a license to display the preprint in perpetuity. It is made available under a CC-BY-NC-ND 4.0 International license .

Nasopharyngeal (NP) swab material was diluted 1:2 with molecular-grade $\mathrm{H}_{2} \mathrm{O}(50 \mu \mathrm{L}$ NP material: $50 \mu \mathrm{L} \mathrm{H}_{2} \mathrm{O}$ ) and mixed in a corresponding well of a 96-well PCR plate. Plates were covered with sealing foil and heated to $95^{\circ} \mathrm{C}$ for $5 \mathrm{~min}$ in a standard thermocycler then cooled to $4^{\circ} \mathrm{C}$. Ten microliters of diluted, heat-extracted sample material was mixed with $15 \mu \mathrm{L}$ of each 1-step PCR master mix consisting of: 1. $1.5 \mu \mathrm{L}$ each $\mathrm{N} 1$ and $\mathrm{N} 2$ primer probe set, $5 \mu \mathrm{L}$ Quantabio Ultraplex 1-Step Toughmix (4x), and $7 \mu \mathrm{L} \mathrm{H}_{2} \mathrm{O}$ per reaction; 2. $1.5 \mu \mathrm{L}$ human RNase$\mathrm{P}$ reaction primer probe mix, $5 \mu \mathrm{L}$ Quantabio Ultraplex 1-Step Toughmix (4x), and $8.5 \mu \mathrm{L} \mathrm{H}_{2} \mathrm{O}$ per reaction. Real-time PCR thermocycling was performed per CDC guidelines. Each sample was screened in a combined $\mathrm{N} 1, \mathrm{~N} 2$ reaction as well as an internal control human RNase-P reaction. Samples with no registered fluorescence for either assay and those with SARS-CoV-2 target fluorescence between 39.5 and 45 cycle thresholds were re-tested using a validated RNA purification kit (Promega Maxwell RSC Viral Total Nucleic Acid Multi-Pack Kit, ASB1330). RNApurified samples were assayed under the same conditions, but with $5 \mu \mathrm{L}$ of purified sample added to each reaction for $20 \mu \mathrm{L}$ total reaction volume.

\section{RESULTS AND DISCUSSION}

\section{Optimizing saliva sample heat inactivation.}

Collected saliva samples may contain infectious SARS-CoV-2 virus and must be rendered safe through viral inactivation ${ }^{11}$. Frequently, a chemical inactivation agent is added to the sample or is present in vials prior to sample collection ${ }^{12}$. However, components of such inactivation buffers are often costly (tris(2-carboxyethyl)phosphine (TCEP) or thermolabile proteinase K) and have seen limited available during the COVID-19 pandemic. Chemical inactivation methods often function in a dual capacity to decrease viral infectivity ${ }^{13}$ and to inactivate the abundant endonucleases that could rapidly degrade SARS-CoV-2 viral RNA (vRNA) and potentially inhibit downstream amplification during the RT-LAMP reaction ${ }^{14}$. The SLAMP method does not require the addition of any chemical agents, using instead a simple heat inactivation procedure that accomplishes viral inactivation. A range of effective temperatures and heating times have been reported $^{15}$ for sputum and other viruses ${ }^{16}$ sometimes with chemical additives prior or post heating ${ }^{17,18}$. In addition, previous work has suggested that SARS-CoV-2 vRNA is stable in human saliva and detectable with molecular-based approaches ${ }^{19}$. However, most previous LAMP studies have used colorimetric detection with or without RNA extraction ${ }^{17,20,21 .}$

To ensure that saliva samples handled within the laboratory are sufficiently inactivated to render them safe for use in the SLAMP method, we explored heating times at a temperature of $95^{\circ} \mathrm{C}$, reported $^{22}$ to most completely inactivate SARS-CoV-2 in viral transport media. A high titer stock of SARS-CoV-2 was diluted in viral growth media in triplicate to a final volume of $200 \mu \mathrm{L}$. The diluted viral supernatant was then heated to $95^{\circ} \mathrm{C}$ for variable lengths of time, ranging from 0 10 min. Infectivity was then measured via plaque assay in which a limiting dilution of virus was inoculated onto susceptible cells to determine the quantity of infectious virus present in each sample (Figure 2A). Non-inactivated virus (Figure 2A, solid black circles) contained $1.21 \times 10^{7}$ $\mathrm{PFU} / \mathrm{mL}$. The same diluted viral supernatant heated at $95^{\circ} \mathrm{C}$ for $3 \mathrm{~min}$ (Figure $2 \mathrm{~A}$, solid black squares) resulted in $3.41 \times 10^{2} \mathrm{PFU} / \mathrm{mL}$ representing a decrease of $\approx 10^{5} \mathrm{PFU} / \mathrm{mL}$. Heating for a total of $5 \mathrm{~min}$ resulted in a further decrease to $5.0 \times 10^{1} \mathrm{PFU} / \mathrm{mL}$ (Figure 2A, solid black upright triangles). The final times of 7 and 10 min resulted in complete inactivation of viral infectivity with no detectable plaques at any dilution.

Similar time points were performed for infectious SARS-CoV-2 spiked into saliva that had tested negative for SARS-CoV-2 (Figure 2B). Spiked dilutions reduced the initial infectious viral titer 
from $1.09 \times 10^{7} \mathrm{PFU} / \mathrm{mL}$ to $8.40 \times 10^{5} \mathrm{PFU} / \mathrm{mL}$ (Figure $2 \mathrm{~B}$, solid black circles). Due to the high number of infectious virus particles present after 3 min of heating at $95^{\circ} \mathrm{C}$ from the previous inactivation studies in viral supernatant, we only evaluated time points $\geq 5$ min for saliva spiked samples. Infectious virus was undetected following exposure to $95{ }^{\circ} \mathrm{C}$ heat for 5,7 , and $10 \mathrm{~min}$, indicating high titers of SARS-CoV-2 can be completely heat-inactivated in saliva in $<5$ min (Figure 2B). Comparable heat inactivation of SARS-CoV-2 is only achieved at $65^{\circ} \mathrm{C}$ after 20 $\min ^{10}$. With the loss of some viral infectivity following the spike into saliva, we suggest a minimum heating time of $10 \mathrm{~min}$ at $95^{\circ} \mathrm{C}$ to ensure samples are fully inactivated before use. In addition, heating at $95^{\circ} \mathrm{C}$ represents a potential $2 \times$ faster option for viral inactivation compared to inactivation times reported for $65^{\circ} \mathrm{C}$.
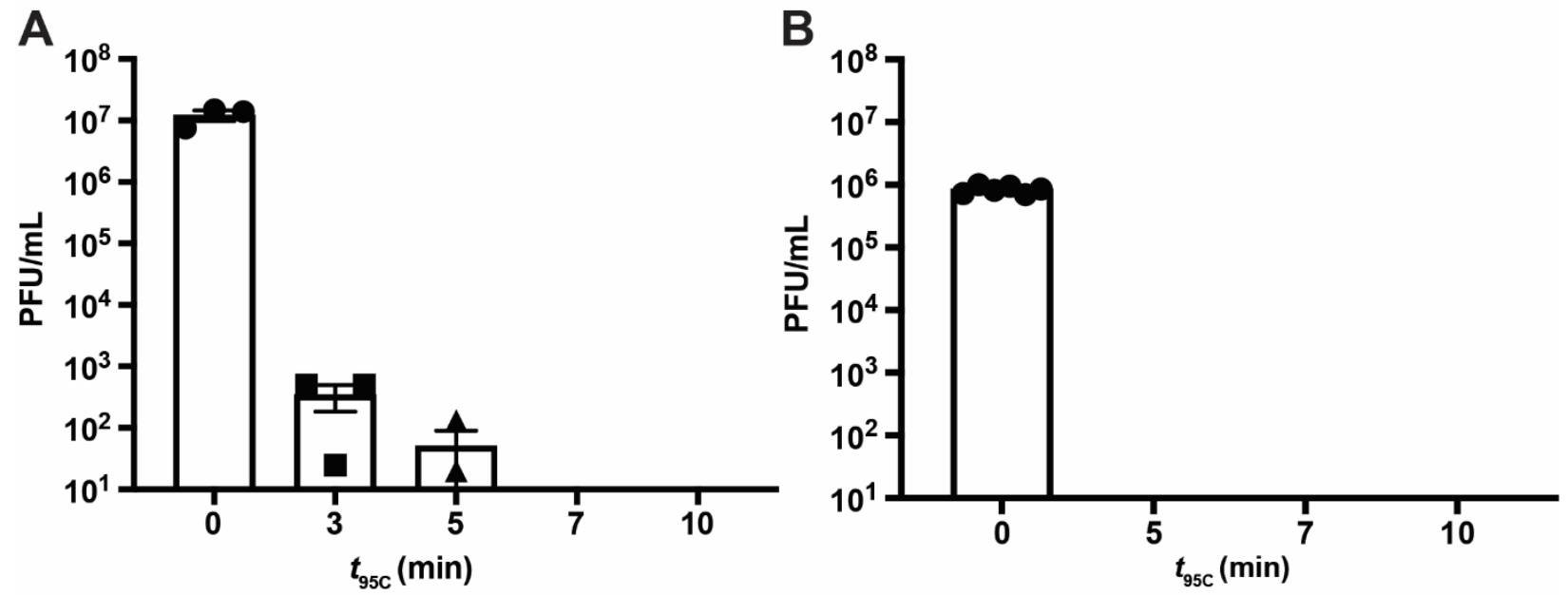

Figure $2.95{ }^{\circ} \mathrm{C}$ heat-inactivation durations and subsequent SARS-CoV-2 virus infectivity. Plaque-forming units (PFU) per $\mathrm{mL}$ after $95{ }^{\circ} \mathrm{C}$ heat inactivation of infectious SARS-CoV-2 for no heating (solid black circles) and 3 (solid black squares), 5 (solid black upright triangles) min in (A) viral growth media and (B) human saliva. All data represent the mean of triplicate samples +/- SEM.

While Infectivity experiments suggest that $5 \mathrm{~min}$ at $95{ }^{\circ} \mathrm{C}$ of heat inactivation is sufficient to eliminate risk of infection, the viral envelope must also be lysed to access vRNA if the most sensitive detection limits are to be achieved. Furthermore, nucleases and inhibitors present in human saliva must also be inactivated to protect free vRNA from degradation ${ }^{23}$ while avoiding vRNA degradation due to prolonged heating. To optimize reaction conditions, we performed SLAMP reactions on raw positive saliva samples (Figure 3 ). Three concentrations of SARSCoV-2-positive saliva were prepared by dilution with negative saliva. The samples were left untreated or were heated at $95^{\circ} \mathrm{C}$ for $5,10,15,20$, and 30 min, then amplified using SLAMP (Figure 3A-3C). Undiluted positive saliva (Figure 3A) amplified under all heating durations, but relative fluorescent detection was low, $\Delta R n<15$. Interestingly, undiluted positive saliva added to a SLAMP reaction, heat inactivated, and lysed for the 45 min duration at $65^{\circ} \mathrm{C}$ exhibited a linear, instead of sigmoidal, increase in relative fluorescence intensity $\triangle R n$ (Figure $3 A$, open blue circles). At 10-fold dilution, all incubation durations resulted in sigmoidal amplification curves (Figure 3B). The unheated positive saliva amplified the slowest (Figure 3B, open blue circles) suggesting that the heat inactivation step is resulting in viral lysis. At 100 -fold dilution, a single sample triplicate incubated at $95{ }^{\circ} \mathrm{C}$ for 5 min failed to amplify (Figure 3C, open red squares). The mean time-to-positive $T p$ values $<T p>$ for each triplicate trial under each dilution and duration were plotted as a function of $95^{\circ} \mathrm{C}$ heating time $t(\mathrm{~min})$ (Figure 3D). As the positive saliva sample is diluted, greater scatter is observed between amplification curves as evidenced by greater standard deviations at all heating durations (Figure 3D, solid green diamonds). 
medRxiv preprint doi: https://doi.org/10.1101/2021.03.31.21254634; this version posted April 5, 2021. The copyright holder for this preprint (which was not certified by peer review) is the author/funder, who has granted medRxiv a license to display the preprint in perpetuity. It is made available under a CC-BY-NC-ND 4.0 International license .

Greater scatter between triplicates is observed as the SLAMP limit of detection (LOD) is approached. 10-fold diluted samples exhibited significant differences between $<T p\rangle$ without heat inactivation and at heating times $t>5 \mathrm{~min}$ (Figure 3D, solid red squares). The undiluted saliva samples exhibit diminishing $<T p>$ as a function of heating time, implying detectable vRNA increased consistently from 5 - 30 min (Figure 4D, solid blue circles). Interestingly, across all dilutions, the 30 min heating time produced $<T p>$ values with low standard deviation and consistent separation of $\approx 2 \mathrm{~min}$. Similar results are observed at $20 \mathrm{~min}$ heating. Therefore, we choose a 15-min heating time at $95{ }^{\circ} \mathrm{C}$ for SLAMP with an additional $\approx 5$ min to allow temperature to ramp-up, closely approximating a 20 min total heating time.
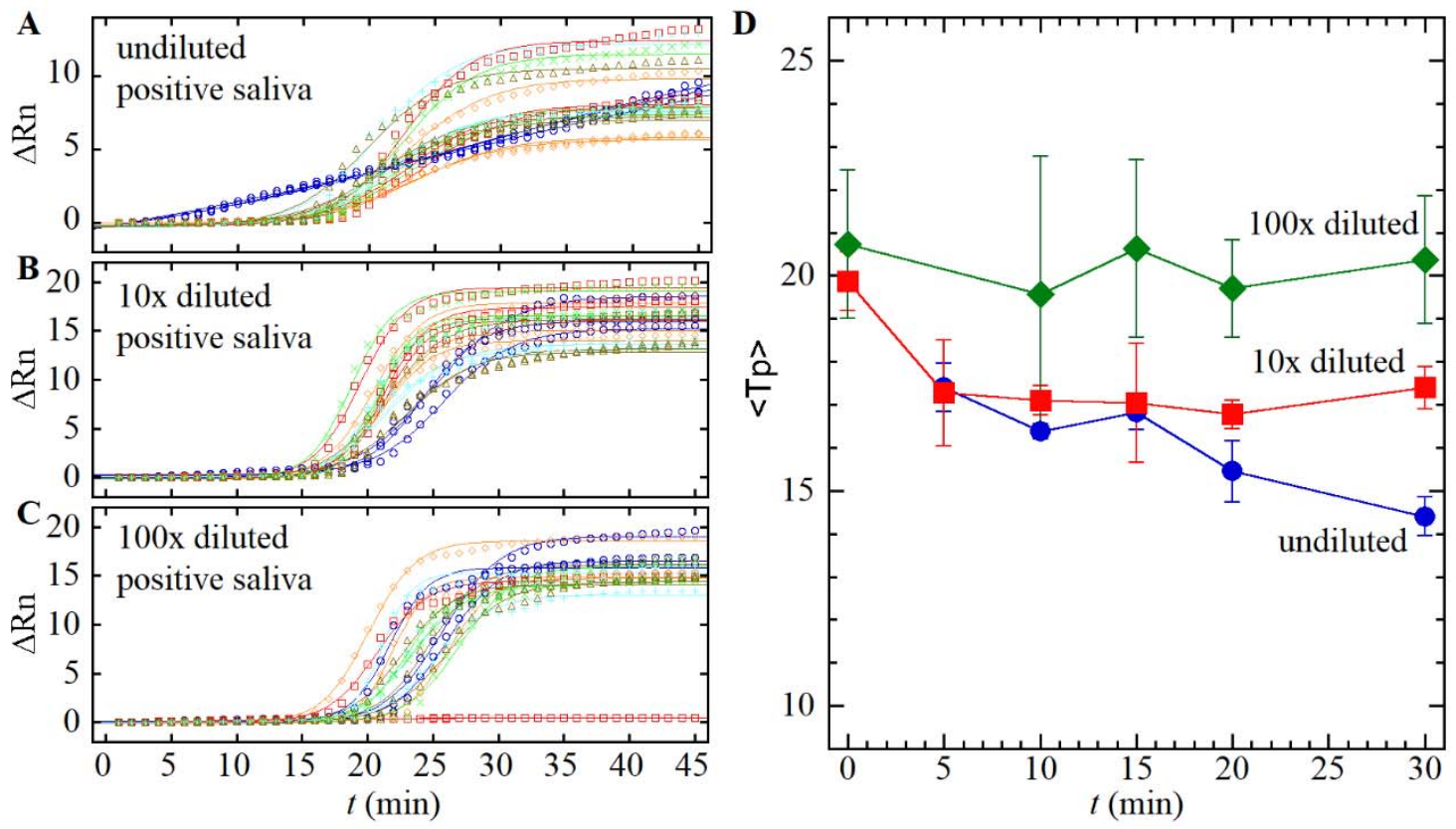

Figure 3. $95{ }^{\circ} \mathrm{C}$ heat inactivation duration optimization of positive saliva sample dilutions. Triplicate SLAMP reactions were performed on $95^{\circ} \mathrm{C}$ heat inactivation for 5 (open red squares), 10 (open orange diamonds), 15 (green diagonal crosses), 20 (light blue upright crosses), and 30 (open brown upright triangles) min in addition to no heating (open blue circles) for (A) undiluted, (B) 10x dilution, and (C) 100x dilution. Solid lines represent RT-LAMP curve fits (see Materials and Methods). (D) Mean time-to-positive $\langle\mathrm{Tp}\rangle$ values as a function of $95^{\circ} \mathrm{C}$ inactivation durations $t$ (min) for undiluted (solid blue circles), 10x diluted (solid red squares), 100x diluted (solid green diamonds) from triplicate data in parts $(\mathrm{A})-(\mathrm{C})$. Error bars represent a single standard deviation. Lines guide the eye.

\section{Comparing testing methods: SLAMP, SalivirDetect, and NP RT-qPCR.}

We compare samples across three different testing methods, SLAMP, SalivirDetect, and the "gold standard" RT-qPCR. Sample collection was performed using nasopharyngeal (NP) swab for RT-qPCR while saliva, shown to provide sufficient viral RNA for detection ${ }^{15}$, was used for both SLAMP and SalivirDetect. Both SalivirDetect and NP RT-qPCR are PCR-based while SLAMP uses isothermal LAMP amplification.

\section{Standard curves and LOD for SLAMP reactions.}

Effective tests for curbing the potential for asymptomatic or presymptomatic spread of SARSCoV-2 must be able to detect the virus reliably and early in the course of infection before the 
medRxiv preprint doi: https://doi.org/10.1101/2021.03.31.21254634; this version posted April 5, 2021. The copyright holder for this preprint (which was not certified by peer review) is the author/funder, who has granted medRxiv a license to display the preprint in perpetuity. It is made available under a CC-BY-NC-ND 4.0 International license .

onset of symptoms ${ }^{24}$. In practice, this requires a test with high sensitivity and specificity at a low limit of detection (LOD). The LOD for the "gold standard" NP qPCR method has been reported ${ }^{25}$ as 10 copies/uL whereas publications have reported ${ }^{14}$ the LOD and sensitivity levels for RTLAMP assays at 2-700 copies/reaction. Furthermore, the sample matrix such as saliva, NP swab, or mid-turbinate swabs can influence the LOD due to the presence of different inhibitors, the variability in sampling methods, differences in infection between sites, or the time of sampling ${ }^{26,27}$.

We evaluated the LOD of SLAMP using spiked saliva samples. To accurately simulate a heatinactivated SARS-CoV-2-positive sample, we harvested saliva from an individual confirmed negative for the presence of SARS-CoV-2 and heated it for $15 \mathrm{~min}$ at $95{ }^{\circ} \mathrm{C}$ to inactivate endonucleases before adding full-length synthetic SARS-CoV-2 RNA (Twist Biosciences). To completely eliminate heat-resistant endonucleases, we added TCEP to saliva for a final reaction concentration of $2.5 \mathrm{mM}$. If the saliva background is not completely inactivated, synthetic RNA quickly becomes degraded and undetectable in minutes by the action of RNases ${ }^{28,29}$ (data not shown).

Synthetic RNA-spiked samples were prepared at concentrations of $10^{5}, 10^{4}, 10^{3}, 10^{2}$, 10, and 1 copies/ $\mu \mathrm{L}$ and amplified using SLAMP (Figure 4A). Amplification curves exhibit characteristic sigmoidal profiles seen in LAMP reactions, with fluorescence detection onsets ranging between $10-20 \mathrm{~min}$. Each concentration is separated by $\approx 2 \mathrm{~min}$ (Figure $4 \mathrm{~A}$, curves). Calculated time-topositive Tp values are used to generate a SLAMP standard curve (Figure 4A, inset). The apparent LOD $=1-10$ copies $/ \mu \mathrm{L}$.

We provide further confirmation of contrived sample RNA concentrations by performing RTqPCR amplification (Figure 4B). The RT-qPCR LOD appears $>1$ copies $/ \mu \mathrm{L}$. The RT-qPCR standard curve (Figure 4B, inset) spans a greater dynamic range of $\mathrm{Ct}$ values compared to the Tp values of RT-LAMP reactions with a significantly lower standard deviation.
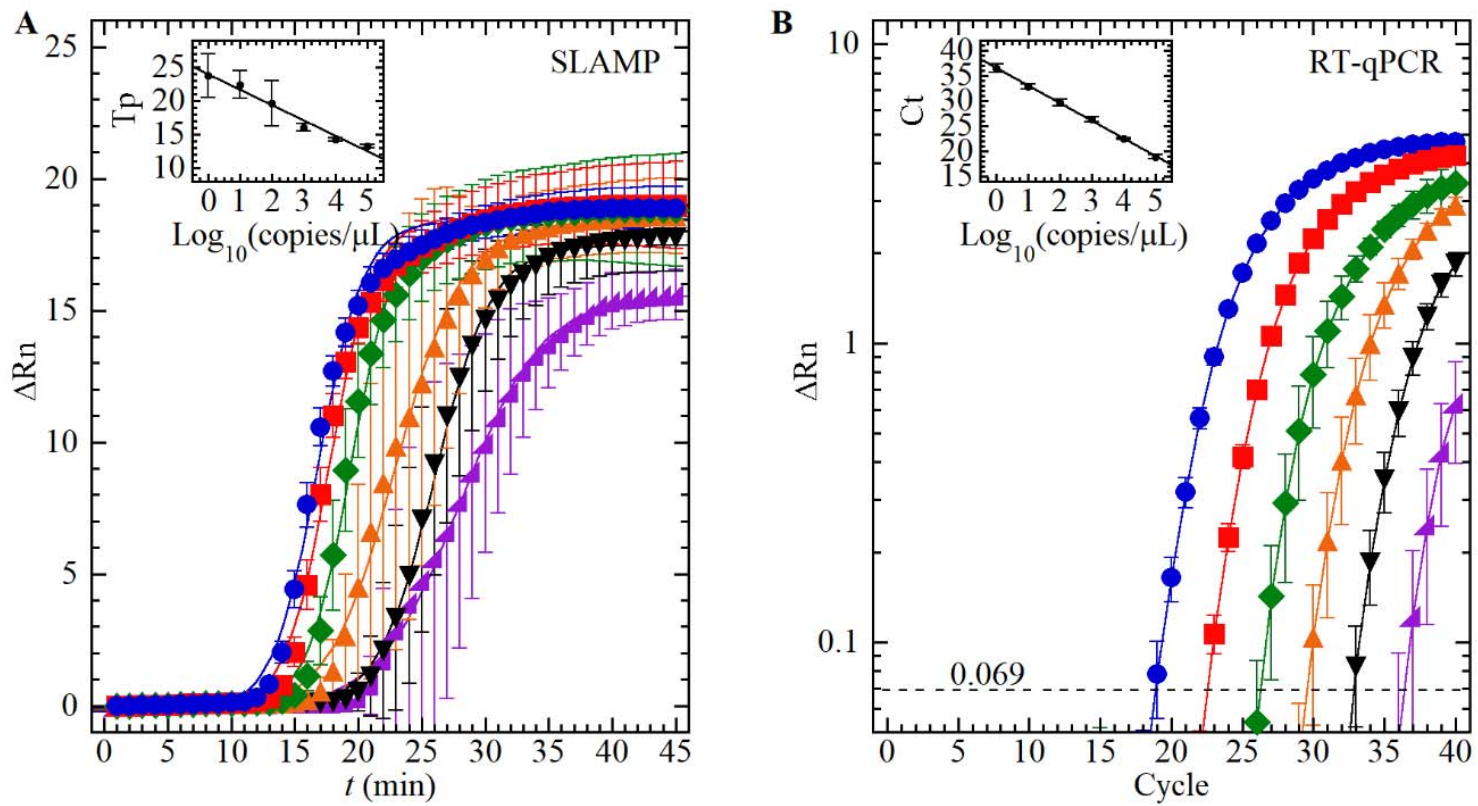

Figure 4. Determining limit of detection (LOD) and standard curves for SLAMP. Contrived saliva samples prepared at $10^{5}$ (solid blue circles), $10^{4}$ (solid red squares), $10^{3}$ (solid green diamonds), $10^{2}$ (solid orange upright triangles), 10 (solid black inverted triangles), and 1 (solid purple right triangles) copies/uL. Synthetic full-length SARS-CoV-2 RNA diluted in inactivated negative human saliva and amplified using (A) SLAMP and (B) NEB Luna Kit RT-qPCR. (A) Relative fluorescence intensity $\Delta \mathrm{Rn}$ recorded as a function of time $t(\mathrm{~min})$. Limit of detection (LOD) lies between 1 and $10 \mathrm{c} / \mu \mathrm{L}$. Inset: SLAMP standard curve 
medRxiv preprint doi: https://doi.org/10.1101/2021.03.31.21254634; this version posted April 5, 2021. The copyright holder for this preprint (which was not certified by peer review) is the author/funder, who has granted medRxiv a license to display the preprint in perpetuity. It is made available under a CC-BY-NC-ND 4.0 International license .

$\mathrm{Tp}=23.99-2.30 \log _{10}$ [copies $\left./ \mu \mathrm{L}\right]\left(R^{2}>0.97\right)$ calculated using time-to-positive Tp values (see Materials and Methods) generated from data in part (A). (B) RT-qPCR standard curve. Ct values determined at $\Delta \mathrm{Rn}=0.069$ cutoff determined using Design \& Analysis Software (see Materials and Methods). Inset: NEB Luna Kit RT-qPCR standard curve Ct $=36.55-$ $3.50 \log _{10}[$ copies $/ \mu \mathrm{L}]\left(R^{2}>0.999\right)$ calculated using $\mathrm{Ct}$ values from part $(\mathrm{B})$.

\section{RT-LAMP reaction optimized using GuHCl and duplex primer sets.}

RT-LAMP reactions involve a minimum of four primers per set to function. The addition of a loop primer pair for a total of six primers has been shown to increase the speed of the reaction. Furthermore, by including multiple 6-primer sets in a single reaction, the sensitivity and speed of the RT-LAMP reaction can be increased significantly.

Saliva is a challenging sample medium for nucleic acid testing, largely due to variability in $\mathrm{pH}^{30}$, ionic strength, and the presence of nucleases that degrade vRNA before it can be detected ${ }^{31}$. RT-LAMP is more resistant to "dirty" samples, including saliva, than traditional RT-qPCR ${ }^{19}$. Here, we tested established methods to increase the sensitivity and speed of the RT-LAMP reaction on saliva using guanidine hydrochloride $(\mathrm{GuHCl})$ and multiplexed primer sets.

Strategies to overcome sensitivity loss associated with saliva sampling include the addition of GuHCl to the RT-LAMP master mix, a strong chaotropic agent used frequently in molecular biology for varied applications including RNA isolation and protein extraction. Low $\mathrm{GuHCl}$ concentrations $(40 \mathrm{mM})$ can be used as additives in the RT-LAMP reaction, facilitating enzyme/nucleic acid interactions and thereby increasing sensitivity without an accompanying reduction in specificity ${ }^{8}$.

We compared triplicate SLAMP reactions of SARS-CoV-2-positive saliva using a single E1 or N2 primer set (Materials and Methods) and duplexed NE primer sets (Figure 5A - 5D) at $10^{3}$ (Figure 5A, open circles), $10^{2}$ (Figure 5B, open squares), and 10 (Figure 5C, open diamonds) genome copies $/ \mu \mathrm{L}$ concentrations $C$. At $10^{3} \mathrm{c} / \mu \mathrm{L}$, every primer set triplicate SLAMP reaction results in amplification and positive detection of SARS-CoV-2. At a ten-fold dilution, the E1 primer set alone begins to perform poorly, failing to amplify 2 triplicates (Figure 5B, open blue squares). Additionally, the $\mathrm{N} 2$ primer set triplicates also begin to lose sensitivity at $100 \mathrm{c} / \mu \mathrm{L}$. While no N2 primer set reactions failed to amplify, one reaction amplified much later (Figure 5B, open red squares). All duplex NE primer reactions amplified (Figure 5B, open orange squares). As the limit of detection is reached at $10 \mathrm{c} / \mu \mathrm{L}$, each primer set condition drops at least a single replicate (Figure $5 \mathrm{C}$ ). However, the NE primer set most accurately amplifies at $<T p>$ appropriate for $10 \mathrm{c} / \mu \mathrm{L}$ (Figure $5 \mathrm{C}$, open orange diamonds). Comparison of $\langle T p>$ values for triplicates under different genome concentrations and primer sets reveal that the duplex NE primer set produces both an accurate prediction of the genome copies/uL and less variability between successful amplifications (Figure 5D, solid green diamonds). The E1 and N2 single primer sets (Figure 5D, solid blue circles and solid red squares, respectively) both exhibit significantly greater scatter and deviation from predicted concentrations based on the SLAMP standard curve.

After establishing that duplex NE primer sets offer greater sensitivity and reproducibility than single $\mathrm{E} 1$ or $\mathrm{N} 2$ primer sets, we evaluated whether the addition of $\mathrm{GuHCl}$ improved amplification reliability. We performed triplicate SLAMP reactions at positive saliva concentrations of 1000 , 100 , and 10 copies/uL SARS-CoV-2 genomes using the duplex NE primer sets and $40 \mathrm{mM}$ GuHCl (Figure 5E, open orange circles, squares, and diamonds, respectively). While the addition of $\mathrm{GuHCl}$ has partially deviated $<\mathrm{Tp}>$ from the standard curve, every replicate amplified and standard deviations were low (Figure 5F). 

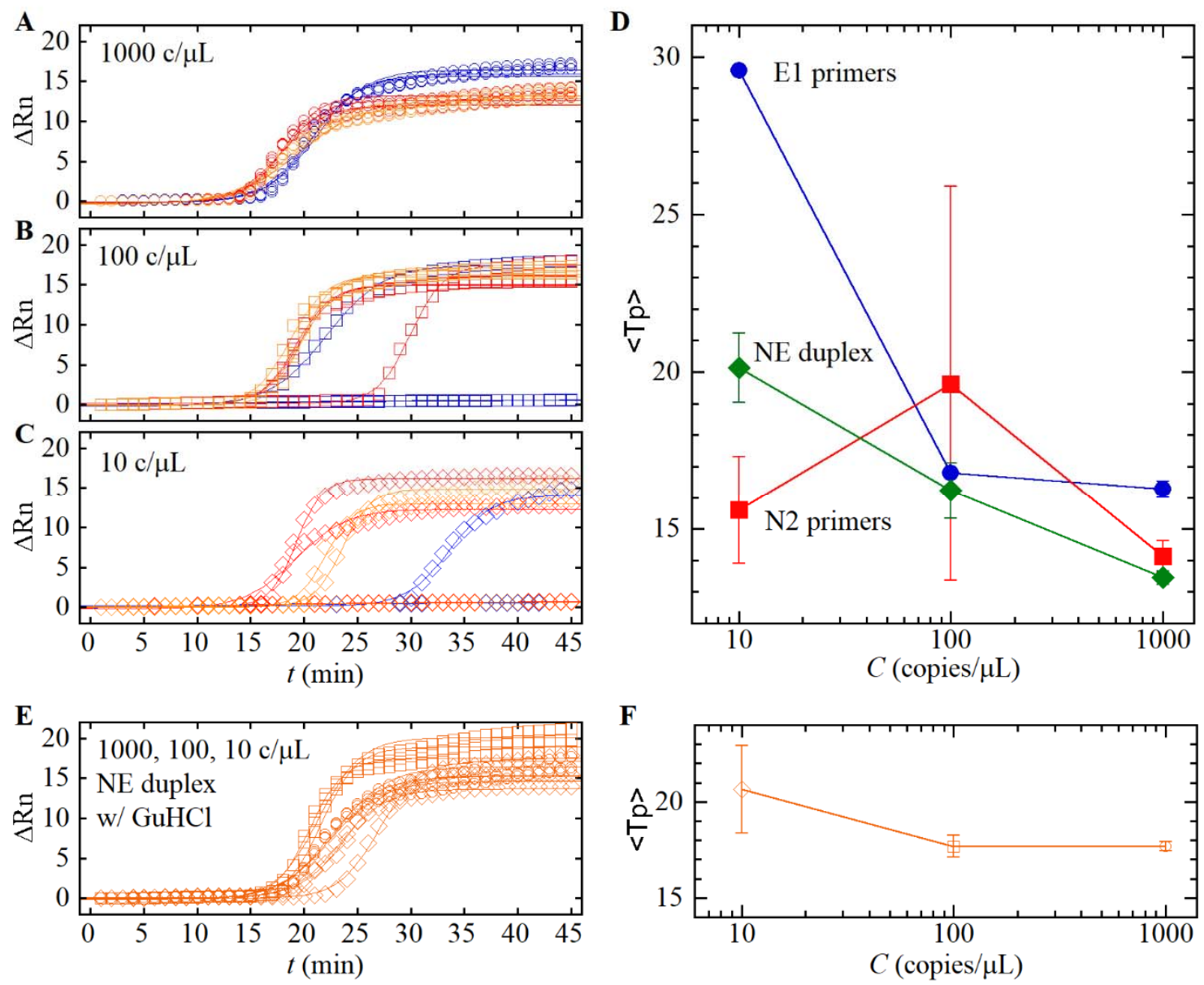

Figure 5. Duplex NE primer set and guanidine HCl (GuHCl) improves sensitivity and speed of SLAMP. Triplicate SLAMP reactions of (A) 1000 (open circles), (B) 100 (open squares), and (C) 10 (open diamonds) copies/ $\mu \mathrm{L}$ positive saliva samples without $\mathrm{GuHCl}$ and only single E1 primer set (blue), single N2 primer set (red), or duplex NE primer sets (orange). Curve fits yield time-to-positive Tp values (see Materials and Methods). (D) $\langle\mathrm{Tp}>$ as a function of genome copies/ $\mu \mathrm{L} C$ for single E1 primer set (solid blue circles), single N2 primer set (solid red squares), and duplex NE primer sets (solid green diamonds) from parts (A) - (C). Error bars represent one standard deviation. Lines guide the eye. (E) Triplicate SLAMP reactions of positive saliva samples at 1000 (open circles), 100 (open squares), and 10 (open diamonds) genome copies/ $\mu \mathrm{L}$ using only duplex NE primer sets (orange) with $40 \mathrm{mM} \mathrm{GuHCl}$. (F) $\langle\mathrm{Tp}\rangle$ as a function of 1000 (open circle), 100 (open square), and 10 (open diamond) genome copies/ $\mu \mathrm{L} C$ for duplex NE primer sets with $40 \mathrm{mM} \mathrm{GuHCl}$ from part (E). Error bars represent one standard deviation. Lines guide the eye.

We demonstrate that the addition of $\mathrm{GuHCl}$, along with the use of a duplex primer set composed of both N2 and E1 primers (see Materials and Methods) in the same reaction, optimizes the saliva RT-LAMP reaction, achieving greater sensitivity and more rapid time-to-result, thereby increasing the utility of SLAMP for more consistent detection of low viral titers in saliva.

With an optimized assay (GuHCI, primers), knowledge of LOD and heating times, we performed our trial study. Volunteers operating at MSU's symptomatic testing site collected samples from 243 individuals who provided NP swabs for CDC RT-qPCR "gold standard" testing and saliva samples for SalivirDetect and SLAMP. A questionnaire (see Materials and Methods) was also 
medRxiv preprint doi: https://doi.org/10.1101/2021.03.31.21254634; this version posted April 5, 2021. The copyright holder for this preprint (which was not certified by peer review) is the author/funder, who has granted medRxiv a license to display the preprint in perpetuity. It is made available under a CC-BY-NC-ND 4.0 International license .

provided to collect self-reported demographic and illness presentation data, in addition to determining whether any foods, drinks, or potential inhibitors were consumed 30 min prior to sample collection.

\section{Demographics, illness presentation, and potential inhibitors in saliva.}

Ages were typical of a campus population (Figure 6A), ranging between 17 and 63 with a median age of 20 . Males comprised $54 \%$ and females $46 \%$ of known sexes, with a single respondent opting not to provide information (Figure 6B). Racial (Figure 6C) and ethnic (Figure 6D) statistics matched well with those of Bozeman, MT as a whole. To the closest percentage, test subjects were comprised of $94 \%$ white and $5 \%$ other races including American Indian, Alaskan Native, Native Hawaiian or Pacific Islander, Asian, and African American, with 1\% opting not to respond. The City of Bozeman 2010 census $^{32}$ reports $92.1 \%$ white and $3.3 \%$ other race, and also similar to our survey, $53 \%$ male and $47 \%$ female. Notably due to drawing largely from college students, the test survey median age of 20 years differed most significantly among all the statistics, compared to 2010 Census data of 27.8 years. Finally, participants self-reported as symptomatic or asymptomatic (Figure 6E). Among these, respondents indicated whether they had knowledge of exposure to a COVID-19-positive individual or not. The majority $70 \%$ of those tested were symptomatic and $54 \%$ of these were aware of contact with a positive individual. Among the asymptomatic 30\% remaining, $6 \%$ were unaware of exposure, with the remaining $94 \%$ seeking tests before symptom onset after becoming aware of their exposure.

Participants were surveyed for potential inhibitors should they have imbibed orally within 30 min of testing (Figure 6F). Among all actions, drinking and tooth brushing dominate followed by eating. Inhibitors, such as mouthwash and gum, are known to interfere with the RT-LAMP reaction $^{33}$. Finally, few respondents reported the use of tobacco (smoking or chewing). It should be noted that in our study, we did not exclude persons who potentially had interference (ate, drank, brushed, etc.) within 30 min of testing. 
medRxiv preprint doi: https://doi.org/10.1101/2021.03.31.21254634; this version posted April 5, 2021. The copyright holder for this preprint (which was not certified by peer review) is the author/funder, who has granted medRxiv a license to display the preprint in perpetuity.

It is made available under a CC-BY-NC-ND 4.0 International license.

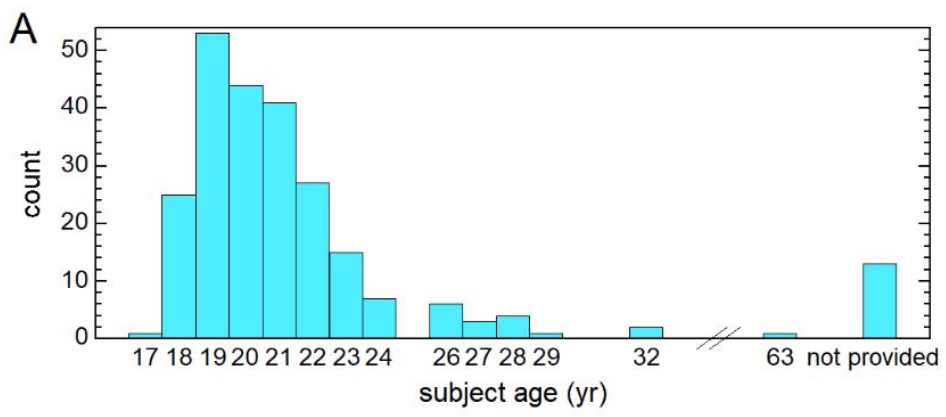

B

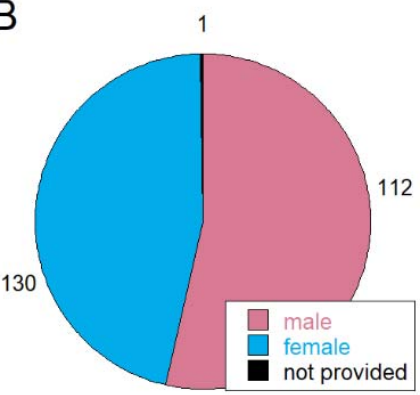

D

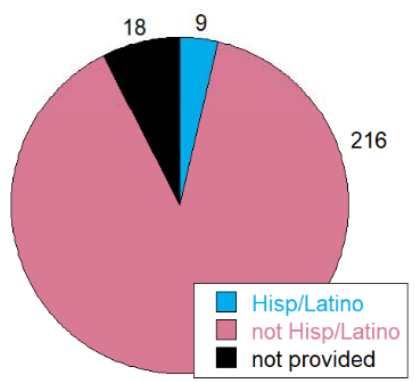

C

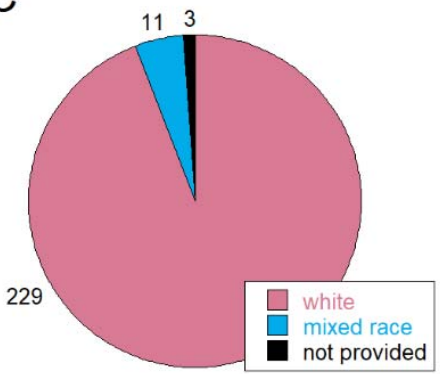

$E$

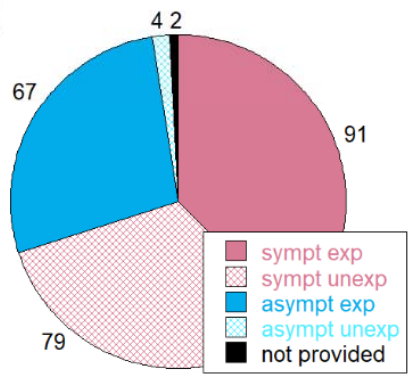

$\mathrm{F}$

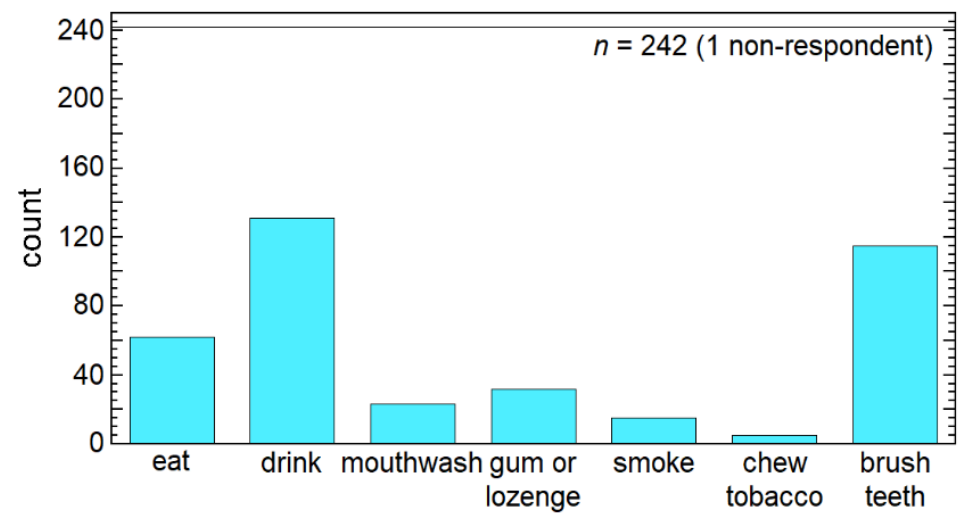

Figure 6. Self-reporting survey results for Saliva LAMP pilot study participants. (A) Distribution of participant ages. (B) Proportion of male and female participants. One non-respondent. (C) Racial demographics of participants. (D) Ethnicity (Hispanic or Latino) breakdown of participants of any race. (E) Self-reported exposed or not exposed to known positive cases for symptomatic and asymptomatic participants. (F) Potential inhibitors engaged in 30 min before testing. Respondents may have selected multiple options. 
medRxiv preprint doi: https://doi.org/10.1101/2021.03.31.21254634; this version posted April 5, 2021. The copyright holder for this preprint (which was not certified by peer review) is the author/funder, who has granted medRxiv a license to display the preprint in perpetuity. It is made available under a CC-BY-NC-ND 4.0 International license .

\section{Self-reported disease presentation and prior SARS-CoV-2 exposure.}

Disease presentation was self-reported by all SLAMP pilot testing volunteers. While the MSU COVID-19 testing site was designated as operating for symptomatic testing only, this was not the case for a proportion of subjects. Thus, individuals who self-reported as currently experiencing symptoms associated with COVID-19 were designated symptomatic while any others were asymptomatic. Additionally, subjects were asked if they had been exposed to any individuals who had recently tested positive for presence of SARS-CoV-2. The unexposed option only refers to an individual's personal knowledge of exposure to someone with a confirmed positive SARS-CoV-2 test while still potentially contagious. A total of 237 of 243 responses fell within three categories: 79 individuals self-reported as symptomatic exposed (Figure 7A-7D), 91 individuals self-reported as symptomatic unexposed (Figure 6E-6H), and 67 individuals self-reported as asymptomatic and exposed (Figure 6I-6L). Remaining responses were from volunteers who had neither exposure nor symptoms and all such cases tested negative across all three testing methods, "gold standard" NP qPCR, SalivirDetect saliva qPCR, and SLAMP saliva RT-LAMP.

Individuals who self-reported as symptomatic and exposed totaled 79 and were composed of 23 positive and 56 negative subjects for a disease prevalence of $29 \%$ between all three testing methods (Figure 7A-7C). However, one test subject was negative in both saliva-based test methods but positive under NP qPCR (Figure 6D, sample ID 98624) and another test subject was positive under SLAMP but negative in both NP and SalivirDetect qPCR (Figure 6D, sample ID 98946).

Symptomatic individuals with no knowledge of potential SARS-CoV-2 exposure numbered 91 in total and had a higher disease prevalence than any other disease presentation category at $33 \%$ under NP qPCR (Figure 6E), 29\% under SalivirDetect (Figure 6F), and 31\% under SLAMP (Figure 6G), except for the SalivirDetect method, which had the same $29 \%$ disease prevalence for all symptomatic individuals. Both saliva methods provided negative results for two samples (Figure $6 \mathrm{H}$ ), suggesting concentrations of SARS-CoV-2 virus or RNA can differ between nasopharyngeal cavity or fluids versus the mouth and saliva.

A total of 67 individuals reported as asymptomatic and exposed, among which $15 \%$ tested positive using NP qPCR (Figure 6I), 18\% tested positive using SalivirDetect (Figure 6J), and $13 \%$ tested positive under SLAMP (Figure 6K). Interestingly, sample IDs 98568 and 24988 were both positive under saliva testing methods, but negative under NP swab (Figure 6L), further suggesting potential differences between sample types. Asymptomatic exposed individuals number the lowest of all categories with the lowest disease prevalence, which is expected considering the likelihood of successful SARS-CoV-2 transmission is not $100 \%$ and other categories were already symptomatic. Asymptomatic exposed individuals are likely the most relevant category for preventing transmission, and good agreement was shown between testing methods. 
medRxiv preprint doi: https://doi.org/10.1101/2021.03.31.21254634; this version posted April 5, 2021. The copyright holder for this preprint (which was not certified by peer review) is the author/funder, who has granted medRxiv a license to display the preprint in perpetuity.

It is made available under a CC-BY-NC-ND 4.0 International license .

A

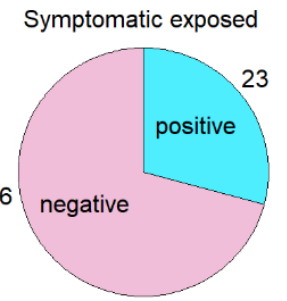

B

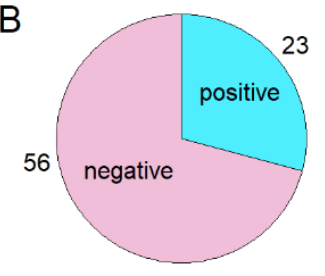

C

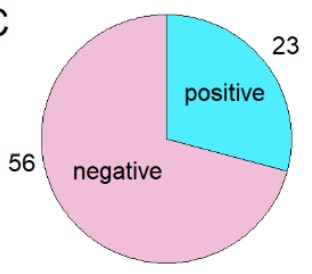

D

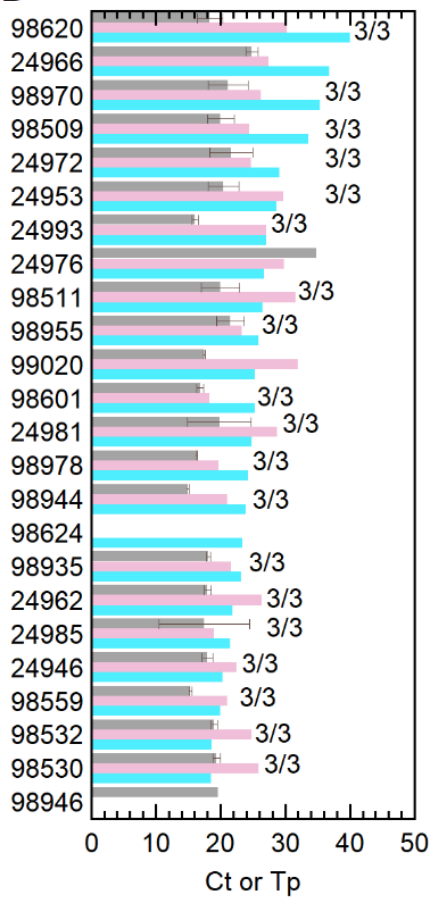

E

Symptomatic unexposed

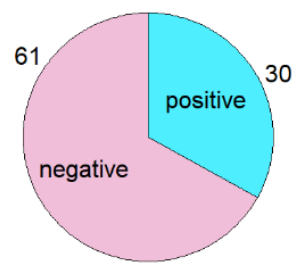

$\mathrm{F}$

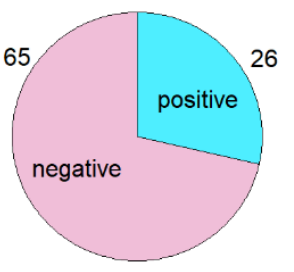

G

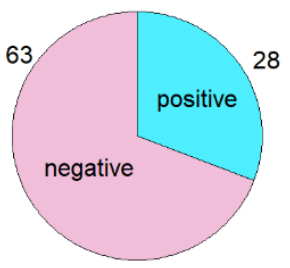

$\mathrm{H}$

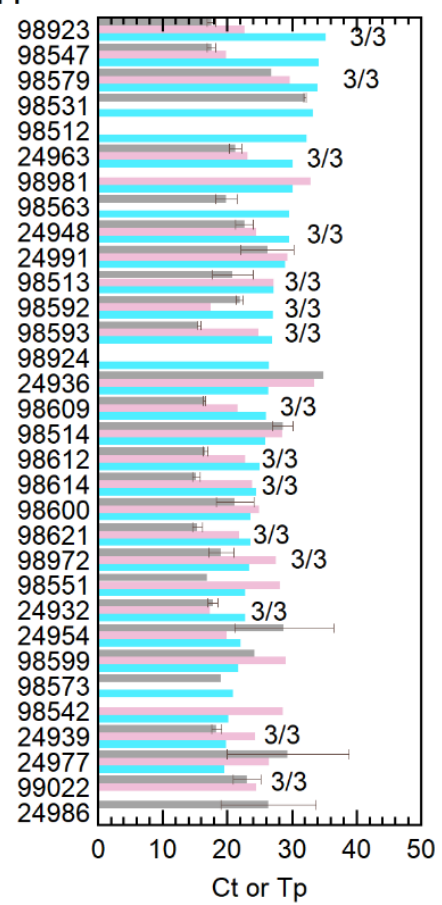

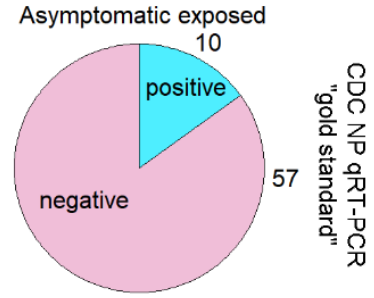

$\mathrm{J}$
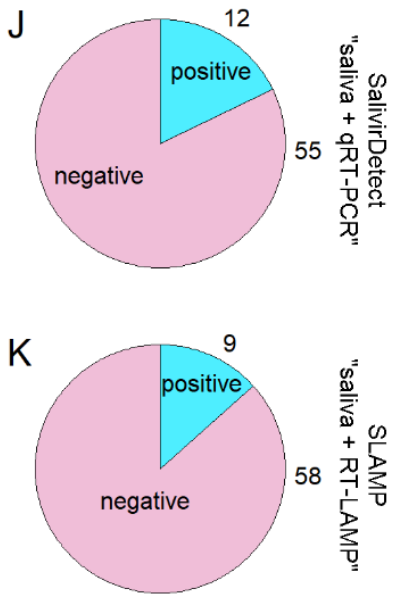

$\mathrm{L}$

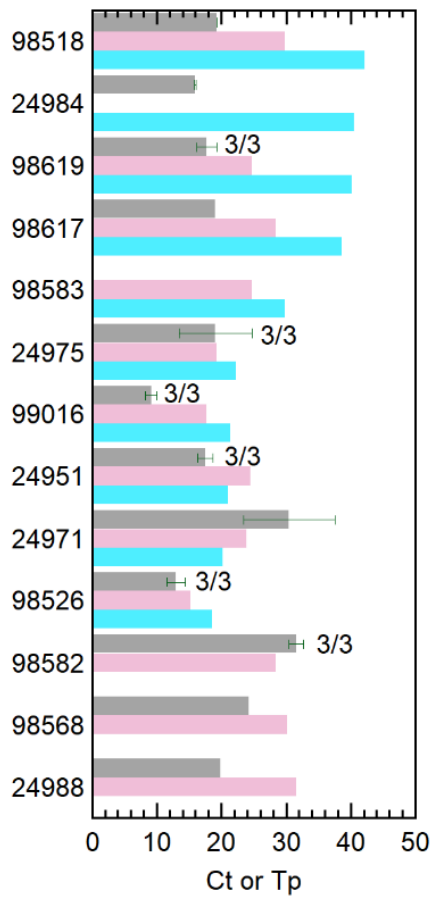

Figure 7. Comparison of exposed symptomatic, unexposed symptomatic, and exposed asymptomatic subjects across three testing methods: "Gold standard" nasopharyngeal (NP) qPCR, SalivirDetect saliva qPCR, and SLAMP saliva RT-LAMP. (A-C), (E-G), and (I-K) pie charts comparing the proportion of positive (blue) and negative (magenta) test results from among 79 individuals who self-reported as symptomatic and exposed, 91 individuals who self-reported as symptomatic and unexposed, and 67 individuals who self-reported as asymptomatic and exposed, respectively, for (A, E, I) NP qPCR, (B, F, J) SalivirDetect saliva qPCR, and (C, G, K) SLAMP saliva RT-LAMP. (D, H, L) cycle threshold Ct for NP (blue) and SalivirDetect (magenta) and mean time-to-positive Tp for SLAMP (gray) for each 5-digit positive sample ID, for exposed symptomatic, unexposed symptomatic, and exposed 
medRxiv preprint doi: https://doi.org/10.1101/2021.03.31.21254634; this version posted April 5, 2021. The copyright holder for this preprint (which was not certified by peer review) is the author/funder, who has granted medRxiv a license to display the preprint in perpetuity. It is made available under a CC-BY-NC-ND 4.0 International license .

asymptomatic individuals, respectively. Error bars indicate one standard deviation. Results are ordered by largest to smallest Ct for NP qPCR. Missing values indicate sample was undetected. Samples with 3/3 positive replicates are indicated, otherwise samples with error bars represent 2/3 positive replicates and no error bars indicates 1/3. Note: total positive samples in parts $\mathrm{D}, \mathrm{H}$, or $\mathrm{L}$ include all positives between the three methods and may be greater than those reported in individual pie charts. Samples reporting asymptomatic unexposed were all negative and excluded from these totals.

\section{Statistical predictions at triplicate, duplicate, or as a single replicate.}

The performance metrics of saliva methods SalivirDetect and SLAMP have been evaluated based on 244 samples and compared to the "gold standard" NP qPCR method. We report the true positive (TP), true negative (TN), false positive (FP), and false negative (FN) counts along with the true positive rate (TPR) and true negative rate (TNR), also called sensitivity and specificity, respectively (Table 1). The sensitivity/specificity (in \%) of SalivirDetect and SLAMP methods are 89/97 and 91/98, respectively. Based on NP qPCR, 65 positive and 179 negative individuals were identified resulting in a disease prevalence of $27 \%$ among the tested cohorts. These include all samples, including those who failed to provide questionnaires.

\begin{tabular}{|c|c|c|c|c|c|c|}
\hline Method & TP & TN & FP & FN & $\begin{array}{c}\text { TPR } \\
(\%)\end{array}$ & $\begin{array}{c}\text { TNR } \\
\text { (\%) }\end{array}$ \\
\hline $\begin{array}{c}\text { SalivirDetect } \\
\text { RT-qPCR }\end{array}$ & 58 & 173 & 5 & 7 & $89,96^{*}$ & 97 \\
\hline $\begin{array}{c}\text { SLAMP } \\
\text { RT-LAMP }\end{array}$ & 59 & 176 & 3 & 6 & $91,95^{\dagger}$ & 98 \\
\hline
\end{tabular}

Table 1. Testing results for both saliva-based methods, SalivirDetect RT-qPCR (N=243) using NP RT-qPCR as the "gold standard" method of comparison. *SalivirDetect sensitivity/specificity increases from 89/97 to 96/97 when a Ct $\geq$ 33 cut-off is applied and samples containing interferences are excluded. ${ }^{\dagger}$ SLAMP sensitivity/specificity increases from 89/98 to 95/98 when samples positive under NP swab but negative under both saliva methods are excluded.

For the assay comparisons between SLAMP and RT-qPCR in Table 1, triplicate assays performed as long as 45 min per individual student were used for SLAMP. Bootstrapping (with 1000 random bootstrap samples) was used to predict sensitivity and specificity when only a single assay or duplicate assays are used for SLAMP, see Figure 8. For each testing scenario, Figure 8 shows how specificity increases as assay length of time is increased. As reported earlier, SLAMP with 3 replicates produced a sensitivity of $91 \%(95 \% \mathrm{Cl}$ : $[83.6 \%, 96.7 \%])$ compared to the NP RT-qPCR result. Bootstrapping predicted a $86 \%$ sensitivity $(95 \% \mathrm{Cl}$ : $[75.4 \%, 93.4 \%])$ for SLAMP with two replicates, and a $77 \%$ sensitivity (95\% Cl: $[67.2 \%, 86.9 \%])$ for SLAMP with a single replicate. 
medRxiv preprint doi: https://doi.org/10.1101/2021.03.31.21254634; this version posted April 5, 2021. The copyright holder for this preprint (which was not certified by peer review) is the author/funder, who has granted medRxiv a license to display the preprint in perpetuity. It is made available under a CC-BY-NC-ND 4.0 International license .
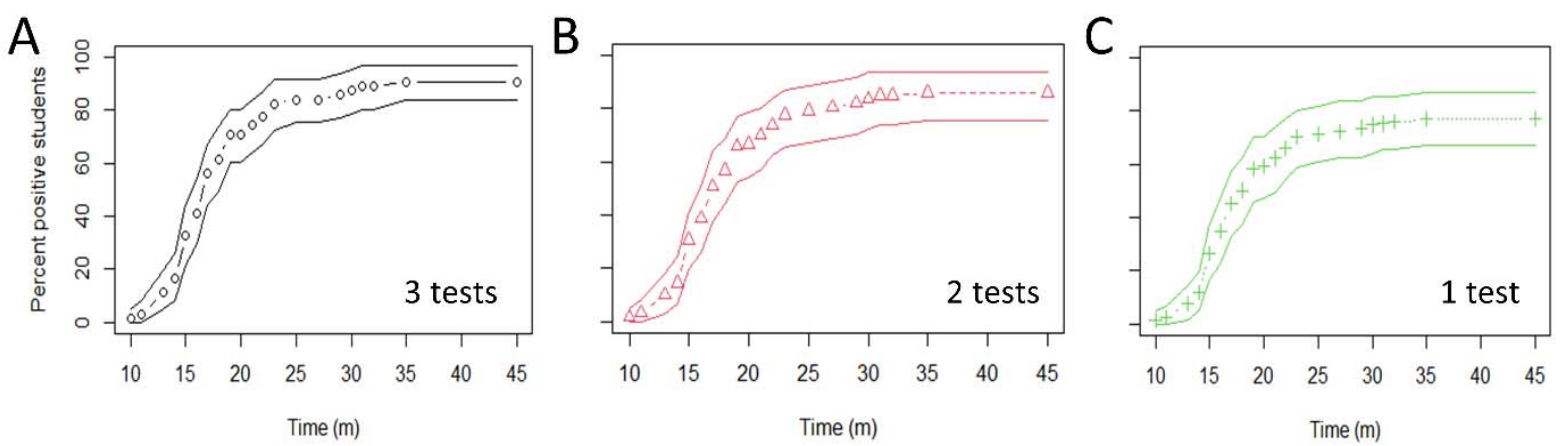

Figure 8. Sensitivity over time different testing scenarios. Percent of SLAMP positive individuals over time based on triplicate (A), duplicate (B) or single (C) assays for SLAMP. Dashed lines indicate the mean. Solid lines indicate $95 \%$ bootstrap confidence intervals.

Based upon an estimated capacity of running six 384-well plates per day (see Materials and Methods), we compare three scenarios of running samples with a single replicate (Figure 9A), in duplicate (Figure 9B), and in triplicate (Figure 9C). For these scenarios, we use the following sensitivity values: 0.91 for triplicate, 0.86 for duplicate, and 0.77 for single replicates. The specificity is assumed to be constant 0.98 for all scenarios. Note this also assumes there are 10 wells in each plate reserved for controls. Given the fixed constraint on the number of tests $(\approx 384$ $\times 6$ ), screening a larger number of individuals can identify more positive cases.

A

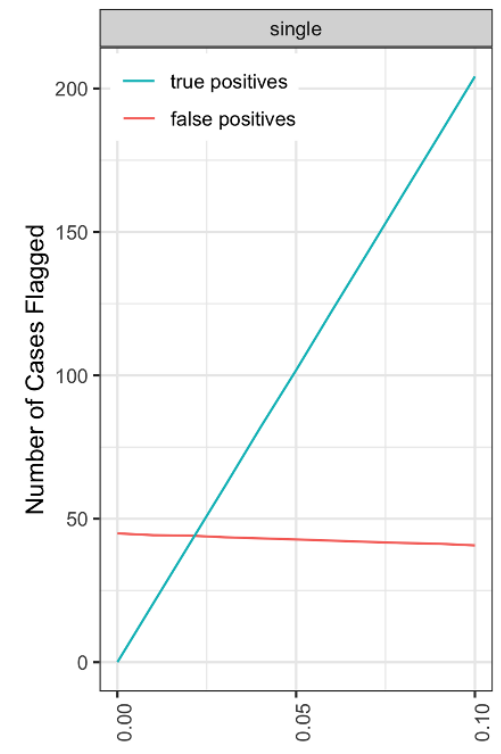

Population Prevalence
B

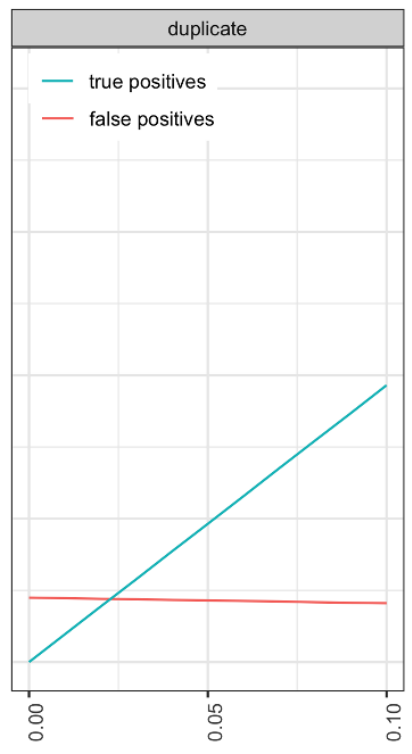

Population Prevalence
C

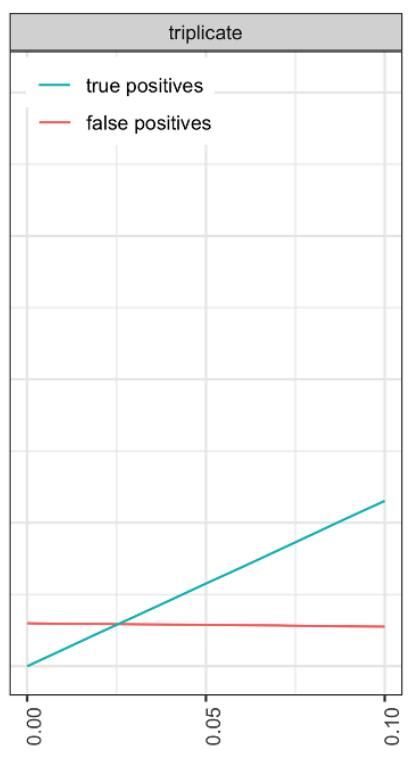

Population Prevalence

Figure 9. Total number of positive cases identified based upon replicate strategy. True positives (blue) and false positives (red) are generated for population disease prevalence between 0.00 and 0.10 for (A) single replicates, (B) duplicates, and (C) triplicates. Based on daily capacity of 6 plates with well size of 384, reserving 10 wells for controls. Assuming sensitivity of 0.91 for triplicate, 0.86 for duplicate, 0.77 for single replicates. Specificity is assumed constant of 0.98 for all three scenarios. 
medRxiv preprint doi: https://doi.org/10.1101/2021.03.31.21254634; this version posted April 5, 2021. The copyright holder for this preprint (which was not certified by peer review) is the author/funder, who has granted medRxiv a license to display the preprint in perpetuity. It is made available under a CC-BY-NC-ND 4.0 International license .

It should be noted that specificity is assumed constant across the three replicate strategies, but is likely lower with single replicates or duplicates than for triplicates. Therefore, running more tests, with a lower specificity can also lead to more false positives that may require confirmatory testing. It should also be noted that running more samples with single replicates are likely to lead to more false negatives, but ideally a high frequency testing strategy would catch those other cases. (Based on validation results, there appears to be a relationship between $\mathrm{Ct}$ value from the PCR and sensitivity, so perhaps these cases have lower viral load and are less infectious). Nonetheless, the data suggest that the SLAMP assay run in triplicate per individual could perform at the level of a clinical diagnostic, while when run as a single replicate could be used as a broad screening tool to identify unknown positives.

\section{CONCLUSIONS and FUTURE DIRECTIONS}

We have presented the results of a pilot study for a SARS-CoV-2 saliva testing method based upon fluorescence-based RT-LAMP nucleic acid amplification. SLAMP was developed to be a streamlined assay directly on saliva and yields $91 \%$ sensitivity and $98 \%$ specificity compared to NP swab without accounting for interference within 30 min of sampling. The saliva sample is simply heated at $95^{\circ} \mathrm{C}$ for 15 min without inactivation buffers and aliquoted directly into an RTLAMP reaction. SLAMP uses a saliva sample which can be collected in $<1$ min, with inexpensive sample tubes or 3D-printable accessories and requires no trained personnel to administer. Dependent upon specific supplies and personnel used, we estimate a single SLAMP assay could cost approximately $\$ 2$ while SLAMP run in triplicate could cost approximately $\$ 6$ (see Table 2).

\begin{tabular}{|c|c|c|}
\hline & SLAMP & SalivirDetect \\
\hline Cost per test (USD) & $2.01^{*}$ & 1.13 \\
\hline Runtime per test & $45 \mathrm{~min}(15 \mathrm{~min}$ heat $/ 30 \mathrm{~min}$ assay $)$ & $3 \mathrm{~h} \mathrm{(45} \mathrm{min} \mathrm{heat/2} \mathrm{h} \mathrm{assay)}$ \\
\hline $\begin{array}{l}\text { Estimated tests per day } \\
\text { (with 1 qPCR machine) }\end{array}$ & 2000 & 380 \\
\hline
\end{tabular}

Table 2. Estimated costs of SLAMP and SalivirDetect SARS-CoV-2 testing methods. ${ }^{*}$ Test cost based on running a single replicate at a capacity of 60,000 tests/month.

Sample inactivation was performed at $95^{\circ} \mathrm{C}$ for $15 \mathrm{~min}$. A heat block was used in this study; but ovens or water baths could be utilized for higher throughput. SLAMP requires no buffers or additives during the heat inactivation step. Heating inactivates SARS-CoV-2 virus, nucleases, and lyses the viral envelope to release vRNA. Nucleic acid amplification was performed using the RT-LAMP reaction and was optimized by the inclusion of $\mathrm{GuHCl}(40 \mathrm{mM})$ to increase sensitivity near the LOD without denaturing enzymes or significantly inhibiting/slowing reaction time. Carry-over contamination is avoided with the inclusion UDG/dUTP to digest any amplicons produced by prior reactions. Finally, a duplex N2 and E1 primer set was chosen for increased specificity and rapidity of the time-to-positive result. Apparent viral concentrations in saliva agreed with previous reports ${ }^{34}$.

An accompanying self-reported survey identifies potential inhibitors, such as foods, drinks, and oral hygiene products, along with providing demographic and disease presentation information. Among the symptomatic who had been exposed to individuals who already tested positive for SARS-CoV-2, we observed a $29 \%$ disease prevalence (as opposed to the total test disease prevalence of $27 \%$ ). The majority of negative tests from this population could have been due to lower viral output over longer times between when first symptoms were observed and sample collection took place, false self-reporting, or higher prevalence of other common causative 
medRxiv preprint doi: https://doi.org/10.1101/2021.03.31.21254634; this version posted April 5, 2021. The copyright holder for this preprint (which was not certified by peer review) is the author/funder, who has granted medRxiv a license to display the preprint in perpetuity. It is made available under a CC-BY-NC-ND 4.0 International license .

agents of respiratory infection such as common cold coronaviruses, rhinovirus, enterovirus, adenovirus, and others. Influenza number have dropped significantly in 2020.

Statistical modeling predicts that SLAMP replicate numbers per test can be lowered from triplicates at the expense of sensitivity. Additionally, reducing the volumes of RT-LAMP reagents needed per test could offset costs associated with including more replicates. Sensitivity $>70 \%$ is suitable for screening testing methods ${ }^{35}$, shown to significantly reduce transmissibility among populations. SLAMP sensitivity becomes $95 \%$ when samples negative in both saliva tests while positive in NP RT-qPCR are excluded from evaluation. These samples exhibit Ct within the detection limits of SalivirDetect and SLAMP, potentially indicating a difference in virus titers between the NP swab and saliva infection sites in the body. SalivirDetect sensitivity increases to $96 \%$ when interfering samples with $\mathrm{Ct} \geq 33$ are excluded. Sample pooling can also be explored as a method to reduce costs and increase throughput.

SLAMP is cheap, quick, and effective and an attractive testing strategy for controlling COVID-19 outbreaks. We anticipate SLAMP and similar saliva-based testing will complement the "gold standard" NP swab test in future pandemics.

\section{FUNDING}

This funding was supported by the State of Montana through the Coronavirus Aid, Relief and Economic Security Act (CARES) Act.

\section{ACKNOWLEDGEMENTS}

We thank Nathan Tanner at New England Biolabs, Kathryn Kundrod in the Richards-Kortum group (Rice University), Paul Hergenrother (UIUC), and the Global LAMP R\&D Consortium led by Christopher Mason (Weill Cornell Medicine) for helpful discussions. We thank MSU students Kyle Hain, Shawna Pratt, Emily Walter, Matthew Fisher, and Jerrica Bursik for sample collection and Donna Gollehon (MSU University Health Partners), Ryan Brickman (MSU Safety and Risk Management), and Ryan Bartlett (MSU Office of Research Compliance) for their assistance throughout the approval process and especially with sample site logistics. We thank the MSU Center for American Indian and Rural Health Equity for the use of the Health Education and Research Bus (HERB) at the sample collection site. HERB is a mobile laboratory and outreach facility made possible with funding from the $\mathrm{NIH}$.

\section{COMPETING INTERESTS}

Connie B. Chang and James N. Wilking are co-founders of ULTSafety, Inc. which has licensed technology from Montana State University and Harvard University relating to this publication.

\section{BIBLIOGRAPHY}

1. Munster, V. J.; Koopmans, M.; van Doremalen, N.; van Riel, D.; de Wit, E., A Novel Coronavirus Emerging in China - Key Questions for Impact Assessment. 2020, 382 (8), 692-694.

2. Bhadra, S.; Maranhao, A. C.; Ellington, A. D., A one-enzyme RT-qPCR assay for SARS-CoV-2, and procedures for reagent production. 2020, 2020.03.29.013342.

3. Buck, M. D.; Poirier, E. Z.; Cardoso, A.; Frederico, B.; Canton, J.; Barrell, S.; Beale, R.; Byrne, R.; Caidan, S.; Crawford, M.; Cubitt, L.; Gamblin, S.; Gandhi, S.; Goldstone, R.; Grant, P. R.; Gulati, K.; Hindmarsh, S.; Howell, M.; Hubank, M.; Instrell, R.; Jiang, M.; Kassiotis, G.; Lu, W.-T.; MacRae, J. I.; Martini, I.; Miller, D.; Moore, D.; Nastouli, E.; Nicod, J.; Nightingale, L.; Olsen, J.; Oomatia, A.; O’Reilly, N.; Rideg, A.; Song, O.-R.; Strange, A.; Swanton, C.; Turajlic, S.; Walker, P. A.; Wu, M.; Sousa, 
C. R. e., Standard operating procedures for SARS-CoV-2 detection by a clinical diagnostic RT-LAMP assay. medRxiv 2020, 2020.06.29.20142430.

4. $\quad$ Esbin, M. N.; Whitney, O. N.; Chong, S.; Maurer, A.; Darzacq, X.; Tjian, R., Overcoming the bottleneck to widespread testing: a rapid review of nucleic acid testing approaches for COVID-19 detection. RNA (New York, N.Y.) 2020, 26 (7), 771-783.

5. Kashir, J.; Yaqinuddin, A., Loop mediated isothermal amplification (LAMP) assays as a rapid diagnostic for COVID-19. Medical Hypotheses 2020, 141, 109786.

6. Lamb, L. E.; Bartolone, S. N.; Ward, E.; Chancellor, M. B., Rapid Detection of Novel Coronavirus (COVID-19) by Reverse Transcription-Loop-Mediated Isothermal Amplification. medRxiv 2020, 2020.02.19.20025155.

7. Yan, C.; Cui, J.; Huang, L.; Du, B.; Chen, L.; Xue, G.; Li, S.; Zhang, W.; Zhao, L.; Sun, Y.; Yao, H.; Li, N.; Zhao, H.; Feng, Y.; Liu, S.; Zhang, Q.; Liu, D.; Yuan, J., Rapid and visual detection of 2019 novel coronavirus (SARS-CoV-2) by a reverse transcription loop-mediated isothermal amplification assay. Clin Microbiol Infect 2020, 26 (6), 773-779.

8. Zhang, Y.; Ren, G.; Buss, J.; Barry, A. J.; Patton, G. C.; Tanner, N. A., Enhancing colorimetric loop-mediated isothermal amplification speed and sensitivity with guanidine chloride. BioTechniques 2020, 69 (3), 178-185.

9. Subramanian, S.; Gomez, R. D., An Empirical Approach for Quantifying Loop-Mediated Isothermal Amplification (LAMP) Using Escherichia coli as a Model System. PLOS ONE 2014, 9 (6), e100596.

10. Loveday, E. K.; Hain, K. S.; Kochetkova, I.; Hedges, J. F.; Robison, A.; Snyder, D. T.; Brumfield, S. K.; Young, M. J.; Jutila, M. A.; Chang, C. B.; Taylor, M. P., Effects of inactivation method on SARS-CoV2 virion protein and structure. bioRxiv 2020, 2020.11.14.383026.

11. Adaway, J. E.; Hawley, J. M.; Lockhart, S. J.; Keevil, B. G., Heat Inactivation of Saliva Samples for the Analysis of Cortisol and Cortisone during the COVID-19 Pandemic. The Journal of Applied Laboratory Medicine 2020, 5 (6), 1413-1416.

12. Rogers, A. A.; Baumann, R. E.; Borillo, G. A.; Kagan, R. M.; Batterman, H. J.; Galdzicka, M. M.; Marlowe, E. M., Evaluation of Transport Media and Specimen Transport Conditions for the Detection of SARS-CoV-2 by Use of Real-Time Reverse Transcription-PCR. Journal of clinical microbiology 2020, 58 (8), e00708-20.

13. Grishin, A. M.; Dolgova, N. V.; Harms, S.; Pickering, I. J.; George, G. N.; Falzarano, D.; Cygler, M., Spike protein disulfide disruption as a potential treatment for SARS-CoV-2. bioRxiv 2021, 2021.01.02.425099.

14. Thompson, D.; Lei, Y., Mini review: Recent progress in RT-LAMP enabled COVID-19 detection. Sensors and Actuators Reports 2020, 2 (1), 100017.

15. Zhu, J.; Guo, J.; Xu, Y.; Chen, X., Viral dynamics of SARS-CoV-2 in saliva from infected patients. J Infect 2020, 81 (3), e48-e50.

16. Sabiiti, W.; Azam, K.; Esmeraldo, E.; Bhatt, N.; Rachow, A.; Gillespie, S. H., Heat Inactivation Renders Sputum Safe and Preserves Mycobacterium tuberculosis RNA for Downstream Molecular Tests. Journal of clinical microbiology 2019, 57 (4).

17. Rabe, B. A.; Cepko, C., SARS-CoV-2 detection using isothermal amplification and a rapid, inexpensive protocol for sample inactivation and purification. Proceedings of the National Academy of Sciences 2020, 117 (39), 24450-24458.

18. Ranoa, D. R. E.; Holland, R. L.; Alnaji, F. G.; Green, K. J.; Wang, L.; Brooke, C. B.; Burke, M. D.; Fan, T. M.; Hergenrother, P. J., Saliva-Based Molecular Testing for SARS-CoV-2 that Bypasses RNA Extraction. bioRxiv 2020, 2020.06.18.159434.

19. Ott, I. M.; Strine, M. S.; Watkins, A. E.; Boot, M.; Kalinich, C. C.; Harden, C. A.; Vogels, C. B. F.; Casanovas-Massana, A.; Moore, A. J.; Muenker, M. C.; Nakahata, M.; Tokuyama, M.; Nelson, A.; 
Fournier, J.; Bermejo, S.; Campbell, M.; Datta, R.; Dela Cruz, C. S.; Farhadian, S. F.; Ko, A. I.; Iwasaki, A.; Grubaugh, N. D.; Wilen, C. B.; Wyllie, A. L., Simply saliva: stability of SARS-CoV-2 detection negates the need for expensive collection devices. medRxiv 2020, 2020.08.03.20165233.

20. Chow, F. W.-N.; Chan, T. T.-Y.; Tam, A. R.; Zhao, S.; Yao, W.; Fung, J.; Cheng, F. K.-K.; Lo, G. C.S.; Chu, S.; Aw-Yong, K. L.; Tang, J. Y.-M.; Tsang, C.-C.; Luk, H. K.-H.; Wong, A. C.-P.; Li, K. S.-M.; Zhu, L.; He, Z.; Tam, E. W. T.; Chung, T. W.-H.; Wong, S. C. Y.; Que, T.-L.; Fung, K. S.-C.; Lung, D. C.; Wu, A. K.-L.; Hung, I. F.-N.; Woo, P. C.-Y.; Lau, S. K.-P., A Rapid, Simple, Inexpensive, and Mobile Colorimetric Assay COVID-19-LAMP for Mass On-Site Screening of COVID-19. Int J Mol Sci 2020, 21 (15), 5380.

21. Lalli, M. A.; Langmade, J. S.; Chen, X.; Fronick, C. C.; Sawyer, C. S.; Burcea, L. C.; Wilkinson, M. N.; Fulton, R. S.; Heinz, M.; Buchser, W. J.; Head, R. D.; Mitra, R. D.; Milbrandt, J., Rapid and Extraction-Free Detection of SARS-CoV-2 from Saliva by Colorimetric Reverse-Transcription LoopMediated Isothermal Amplification. Clinical Chemistry 2020, 67 (2), 415-424.

22. Pastorino, B.; Touret, F.; Gilles, M.; de Lamballerie, X.; Charrel, R. N., Heat Inactivation of Different Types of SARS-CoV-2 Samples: What Protocols for Biosafety, Molecular Detection and Serological Diagnostics? Viruses 2020, 12 (7), 735.

23. Park, N. J.; Li, Y.; Yu, T.; Brinkman, B. M. N.; Wong, D. T., Characterization of RNA in saliva. Clinical chemistry 2006, 52 (6), 988-994.

24. Arons, M. M.; Hatfield, K. M.; Reddy, S. C.; Kimball, A.; James, A.; Jacobs, J. R.; Taylor, J.; Spicer, K.; Bardossy, A. C.; Oakley, L. P.; Tanwar, S.; Dyal, J. W.; Harney, J.; Chisty, Z.; Bell, J. M.; Methner, M.; Paul, P.; Carlson, C. M.; McLaughlin, H. P.; Thornburg, N.; Tong, S.; Tamin, A.; Tao, Y.; Uehara, A.; Harcourt, J.; Clark, S.; Brostrom-Smith, C.; Page, L. C.; Kay, M.; Lewis, J.; Montgomery, P.; Stone, N. D.; Clark, T. A.; Honein, M. A.; Duchin, J. S.; Jernigan, J. A., Presymptomatic SARS-CoV-2 Infections and Transmission in a Skilled Nursing Facility. New England Journal of Medicine 2020, 382 (22), 2081-2090.

25. Ravi, N.; Cortade, D. L.; Ng, E.; Wang, S. X., Diagnostics for SARS-CoV-2 detection: A comprehensive review of the FDA-EUA COVID-19 testing landscape. Biosens Bioelectron 2020, 165, 112454-112454.

26. Wang, W.; Xu, Y.; Gao, R.; Lu, R.; Han, K.; Wu, G.; Tan, W., Detection of SARS-CoV-2 in Different Types of Clinical Specimens. JAMA 2020, 323 (18), 1843-1844.

27. Mallett, S.; Allen, A. J.; Graziadio, S.; Taylor, S. A.; Sakai, N. S.; Green, K.; Suklan, J.; Hyde, C.; Shinkins, B.; Zhelev, Z.; Peters, J.; Turner, P. J.; Roberts, N. W.; di Ruffano, L. F.; Wolff, R.; Whiting, P.; Winter, A.; Bhatnagar, G.; Nicholson, B. D.; Halligan, S., At what times during infection is SARS-CoV-2 detectable and no longer detectable using RT-PCR-based tests? A systematic review of individual participant data. BMC Medicine 2020, 18 (1), 346.

28. Roy, K. M.; Bagg, J.; McCarron, B., The effect of saliva specimen collection, handling and storage protocols on hepatitis C virus (HCV) RNA detection by PCR. Oral diseases 1999, 5 (2), 123-7.

29. Gomes-Keller, M. A.; Gönczi, E.; Tandon, R.; Riondato, F.; Hofmann-Lehmann, R.; Meli, M. L.; Lutz, H., Detection of Feline Leukemia Virus RNA in Saliva from Naturally Infected Cats and Correlation of PCR Results with Those of Current Diagnostic Methods. Journal of clinical microbiology 2006, 44 (3), 916 922.

30. Choi, J. E.; Lyons, K. M.; Kieser, J. A.; Waddell, N. J., Diurnal variation of intraoral pH and temperature. BDJ Open 2017, 3 (1), 17015.

31. Nunes, L. A. S.; Macedo, D. V. d., Saliva as a diagnostic fluid in sports medicine: potential and limitations. Jornal Brasileiro de Patologia e Medicina Laboratorial 2013, 49, 247-255.

32. 2019: American Community Survey 5-Year Estimates Data Profiles. 2019.

33. Zayats, T.; Young, T. L.; Mackey, D. A.; Malecaze, F.; Calvas, P.; Guggenheim, J. A., Quality of DNA extracted from mouthwashes. PloS one 2009, 4 (7), e6165-e6165. 
medRxiv preprint doi: https://doi.org/10.1101/2021.03.31.21254634; this version posted April 5, 2021. The copyright holder for this preprint (which was not certified by peer review) is the author/funder, who has granted medRxiv a license to display the preprint in perpetuity.

It is made available under a CC-BY-NC-ND 4.0 International license .

34. To, K. K.-W.; Tsang, O. T.-Y.; Yip, C. C.-Y.; Chan, K.-H.; Wu, T.-C.; Chan, J. M.-C.; Leung, W.-S.; Chik, T. S.-H.; Choi, C. Y.-C.; Kandamby, D. H.; Lung, D. C.; Tam, A. R.; Poon, R. W.-S.; Fung, A. Y.-F.; Hung, I. F.-N.; Cheng, V. C.-C.; Chan, J. F.-W.; Yuen, K.-Y., Consistent Detection of 2019 Novel Coronavirus in Saliva. Clinical Infectious Diseases 2020, 71 (15), 841-843.

35. Bujang, M. A.; Adnan, T. H., Requirements for Minimum Sample Size for Sensitivity and Specificity Analysis. J Clin Diagn Res 2016, 10 (10), YE01-YE06. 